\title{
Cracking Down on Bribery
}

\author{
Sheheryar Banuri ${ }^{\mathrm{a}}$ and Catherine Eckel ${ }^{\mathrm{b}}$ \\ ${ }^{a}$ Development Economics Research Group, World Bank \\ 1818 H St NW, MC 3-356, Washington, DC, 20433 \\ ${ }^{\mathrm{b}}$ Department of Economics, Texas A\&M University \\ 4228 TAMU, College Station, TX, 77845
}

December 30, 2014

Corresponding Author: Sheheryar Banuri; sbanuri@gmail.com; Development Economics

Research Group, World Bank, 1818 H St NW, MC 3-356, Washington, DC, 20433; Tel: 210394-5515; Fax: 202-522-4881

\begin{abstract}
Do crackdowns on bribery impact corrupt behavior in the long run? In this paper we observe the long-run impact of a short-term punishment institution (i.e., a crackdown) on bribery behavior in a lab setting. We conduct lab experiments in two countries with cultures that differ in corruption norms, and which experience very different levels of bribery: the US and Pakistan. Bribery is implemented in the laboratory as a repeated three-player sequential game, consisting of a firm, a government official and a citizen. The design contains three phases: pre-crackdown, crackdown, and post-crackdown. Results show that post-crackdown behavior is not significantly different from the pre-crackdown behavior in either country. We conclude that short-term crackdowns may impact behavior in the short run, depending on the strength of the existing corruption norms in the country. More importantly, in our setting crackdowns are completely ineffective in the long run, as corrupt behavior rebounds to pre-crackdown levels.
\end{abstract}

Keywords: Bribery, Corruption, Experiments, Punishment, Culture JEL Classification Codes: C91, D73, K42, Z13 


\section{Introduction}

Because corruption is seen as an important impediment to growth, governments implement a variety of policies to combat its effects. These include citizen advocacy, public expenditure tracking surveys, independent watchdog agencies, and large-scale corruption crackdowns. Anti-corruption reforms are costly, in that they require substantial expenditures in terms of manpower and time, as well as large amounts of political capital, to sustain the intervention. Most reforms begin with a period of high intensity and scrutiny, but because this level of activity is not sustainable, it is followed by either a partial or complete retraction. These temporary "crackdowns" occur very frequently in countries where corruption is an important issue, suggesting that punctuated corruption crackdowns may be viewed as effective in changing expectations or norms of behavior. ${ }^{1}$ However, they may have little long run impact, with corrupt behavior rebounding when the crackdown phase is over. It even is possible that crackdowns exacerbate the corruption problem by crowding out existing intrinsic motives against corruption. ${ }^{2}$

In this paper, we use lab experiments to investigate whether corruption crackdowns inhibit or exacerbate corruption in the long run. We observe the long-run impact of a short-run punishment institution (i.e., a crackdown) on one particular type of corrupt transaction: bribery. ${ }^{3}$ Crackdowns in developing countries usually emerge in conjunction with elections, or with actual or anticipated changes in political conditions in response to scandals, discontent among the populace, or attempts to de-legitimize regimes (Brinkerhoff and Kulibaba 1996; Kpundeh, 1999). These crackdowns contain differing combinations of rhetoric and substance, but share a common feature that reforms typically break down after an initial period of high impact. For example, Dininio (2005) presents the case of La Paz, Bolivia, where anti-corruption reforms were introduced, championed by the mayor. Once the mayor left office, however, corrupt practices returned in force. Similarly, Di Tella and Schargrodsky (2003) present the case of Buenos Aires,

\footnotetext{
${ }^{1}$ For example, Lui (1983) reports 304 cases in China over a period of just four years resulting from multiple crackdowns on corrupt practices as reported in the media. Di Tella and Schargrodsky (2003) provide an example in Argentina, and Dininio (2005) provides examples in Bolivia, Venezuela, and Italy. In recent times China has signaled intent to crack down by prosecuting a high profile politician (Bo Xilai) due to corruption (Buckley, 2013). 2 A number of studies show that fines can crowd out intrinsic motives for refraining from "bad" behavior, with short- and long-run consequences (e.g., Gneezy and Rustichini 2000). See fn. 6.

${ }^{3}$ Corruption is defined as the "use of public office for private gain" (Jain 2001). Bribery constitutes one aspect of corruption, and requires a payment by an interested party to a government official in exchange for benefits at a cost to a third party. Bribery, in and of itself, may be welfare-neutral, welfare-enhancing, or welfare-reducing, depending on the cost it imposes on parties external to the transaction (Cameron et al. 2009).
} 
where a crackdown on corruption decreased corrupt behavior, only for it to rebound once the intensity of monitoring was lowered.

Aside from Di Tella and Schargrodsky (2003), however, little is known about the effects of these crackdowns on overall corruption levels due to the absence of data that can be used to evaluate such interventions. Some evidence suggests that if reforms are not sustained, recorruption (or backsliding) occurs (e.g. Dininio, 2005). From the perspective of standard economic theory, the decision to engage in corrupt behavior is made based on the (extrinsic) costs and rewards of doing so, leading to the expectation that post-crackdown behavior will return to pre-crackdown levels (Becker 1968).

Intrinsic motives may play a role in the decision to refrain from corrupt behavior in that an individual incurs "moral costs" by engaging in corruption (Abbink, 2005, among others). Recent research on corruption emphasizes non-pecuniary motives in corrupt transactions, and highlight differences in levels of corruption and response to policy changes across cultures (Banuri and Eckel 2012; Abbink and Serra 2012). For example, Fisman and Miguel (2007) show that the number of diplomats with unpaid parking tickets in New York correlates strongly with the corruption level of their country of origin. Cameron et al. (2009) demonstrate that the propensity both to practice and to punish corruption differs by culture, and that the variation in corruption by gender also depends on culture. Barr and Serra (2010) find that individuals originating from corrupt countries are more likely to engage in corrupt acts in a lab setting. ${ }^{4}$

The implication of this line of research is that intrinsic motives and norms are important, and policies should be designed accordingly (Bardhan 2006). ${ }^{5}$ If intrinsic motives play a role in abstaining from corruption, then even a short-term policy has the potential to impact long-run behavior in a positive way. Crackdowns may reduce corruption in the long run, if the crackdown signals a new norm, which is then internalized by the corrupt agents. However, it is also possible that a crackdown may exacerbate the corruption problem by crowding out "good" motivations. ${ }^{6}$

\footnotetext{
${ }^{4}$ For theoretical research in this area, see Hauk and Saez-Marti (2002). For empirical work, see Licht et al. (2007).

${ }^{5}$ Intrinsic motives and norms are related concepts. A norm of corruption constitutes an expectation of corrupt behavior within the society. Intrinsic motivations depend on social norms: the propensity to engage in corruption is dependent upon the behavior of peers and collective reputations (Tirole 1996). As Bicchieri and Muldoon (2011) point out, policy interventions can serve to change potentially harmful norms that are prevalent in a society. ${ }^{6}$ Motivation crowding theory (Frey and Jegen 2001) provides conditions under which crowding-out occurs. Interventions designed to limit behavior crowd out intrinsic motivation, while interventions designed to support behavior crowd in intrinsic motivation. This crowding out may have long term effects, making institutions that impact intrinsic motives particularly worthy as an area of inquiry. An example of the perverse effect of incentives is Gneezy and Rustichini (2000), who test the short- and long-run impact of implementing a fine on parents who arrive
} 
In either case, differences in norms may impact the post-crackdown effect of a policy. In countries with high levels of corruption and robust norms supporting corruption, the long run impact of a short-run intervention is likely to be small.

The central question addressed in this study is whether a crackdown has long-term effects. In a companion study we demonstrate the effectiveness of a punishment regime in combating bribery (Banuri and Eckel 2014). This paper focuses instead on the post-crackdown period: Once a crackdown regime is removed, does it have a lasting impact on behavior? Furthermore, do the effects vary by culture: that is, does the crackdown have different postcrackdown effects in societies with weak corruption norms versus societies with strong corruption norms?

Laboratory experiments are particularly useful for assessing policy changes where field data are limited. This paper tests directly the long-term impact of a short-term punishment regime in the lab. By using the lab, we implement a "clean test" of a policy change, removing all other confounding factors that affect outcomes in the field. The use of the lab to study corruption has its share of critics, however. In particular, there is considerable debate about using laboratory methods to study complex social phenomena such as corruption and social norms. Laboratory experiments often implement simplified versions of a phenomenon. Detractors argue that such simplification is inappropriate, as it removes necessary contextual richness.

Furthermore, inferring long-term impacts in a lab context may also be inappropriate, as remarked by Gneezy and List (2006). Perhaps the strongest critique of lab studies in this arena is its weak external validity, particularly when using developed-country subjects. We attempt to account for this potential shortcoming by using subjects from two countries.

The US and Pakistan are selected as venues for the study due to their differences in overall perceptions of corruption and experience with bribery. ${ }^{7}$ US subjects constitute a sample from a society with weak norms of corruption: here petty corruption is relatively rare, and tolerance for it is low. In contrast, Pakistani subjects constitute a sample from a society with strong norms of corruption: here corruption (petty corruption in particular, but grand corruption

late to collect their children from a day-care center. They find that the fine increases the number of parents who arrive late, and its subsequent removal fails to restore the previous pattern of behavior. Implementation of the fine crowds out intrinsic motivation, and this effect persists after the fine is removed. See Gneezy et al. (2011) for an excellent review of when and how incentives work to modify behavior. Ryan and Deci (2000) discuss the same issues from a psychological perspective; see Deci at al. (1999) for a meta-analysis of 128 such studies.

${ }^{7}$ See Banuri and Eckel (2014) for a more extensive discussion of sample differences in student populations in these two countries in experience with corruption. 
as well) is frequent and expected (Fisman and Miguel 2007; Kaufmann et al. 2005; Treisman 2007; Transparency International 2011). The experiment uses a repeated game with stable partners, consisting of three players: a firm, which can initiate a bribe; a government official, which can provide a favor to the firm; and a citizen, representing a third party that is impacted by the actions of the government official. We use a within-subjects ABA design, with the first 10 rounds of the experiment having no possibility of punishment (called the "pre-crackdown phase"). The second 10 rounds introduce the possibility of punishment ("crackdown phase"); here the citizen can choose to punish either the firm or the government official, or both, at a cost to themselves. The final 10 rounds are identical to the first; i.e., the punishment institution is removed and behavior is then observed ("post-crackdown phase"). Our focus is to compare bribery in the first 10 rounds with the final 10 rounds in order to test for differences after the crackdown has ended.

Our findings show that crackdowns have some impact on bribery behavior in the short term, particularly in low corruption settings (while enforcement is active), but behavior returns to pre-crackdown levels during the post-crackdown phase. These results favor the economists' view that corruption is determined by extrinsic factors. Short run institutions are largely ineffective in altering behavior in the long run in both high and low corruption settings. Sustained legal enforcement may be necessary to constrain corruption, even in societies with weak norms.

The rest of the paper proceeds as follows. The next section contains a brief review of recent literature on experiments in corruption, culture, and social norms. In subsequent sections we describe the experimental design, implementation, and results. The final section concludes.

\section{Related Literature}

Economists have sought a deeper understanding of the role of norms and culture in corrupt activity, and several such studies illustrate the value of the lab as a venue for studying corruption. Abbink et al. (2002) conduct some of the first lab experiments exploring the role of extrinsic motives on corruption. Using a repeated two-player game consisting of a firm and a government official, they show that exogenously-imposed punishment (with a very low probability) significantly reduces subjects' propensity to engage in corrupt acts. However, if corruption generates negative externalities for other participants, this does little to discourage bribery. Abbink (2004) further shows that staff rotation is a successful policy intervention that 
reduces the overall level of bribery. Finally, Abbink and Hennig-Schmidt (2006) compare the use of loaded language (i.e. the use of the term 'bribe') in instructions and find no discernible difference from a more neutral framing. Our design is informed by this research. ${ }^{8}$

In a field setting that parallels the experimental design presented here, Di Tella and Schargrodsky (2003) observe medical supply purchasing behavior of hospital employees before and after a corruption crackdown in Buenos Aires, Argentina. Using price data on medical inputs, they argue that higher reported prices constitute embezzlement by employees, and are able to show that an increase in monitoring has an immediate impact on prices, though the impact diminishes over time as monitoring decreases. However, prices do not return to precrackdown levels. They show that the long run impact on prices is due to continued monitoring in the post-crackdown phase, as well as higher compensation for employees (respondents that are paid higher wages are less likely to purchase inputs at inappropriately high prices), rather than a change in norms of behavior. This result illustrates the importance of extrinsic incentives: embezzlement responds to monitoring. However, higher salaries also play an important role, and in combination with the greater threat of punishment, yield a discernible change in behavior. One issue with Di Tella and Schargrodsky (2003) is that they use the crackdown as a backdrop to examine the role of wages in constraining corruption. However, the independent effect of the crackdown - in terms of raising awareness, removing worst offenders, changing motives and norms - cannot be identified. We add to the literature on the effect of anti-corruption policies by isolating the effect of crackdowns on long-run, post-crackdown behavior.

Experiments also examine the impact of intrinsic motives and cultural norms on behavior. Cameron et al. (2009) conduct a cross-cultural experiment on bribery using subjects from four countries (Australia, India, Indonesia, and Singapore) in a one-shot three-player bribery game. Their treatments vary the level of punishment and welfare effects of bribes. They find similar propensities to engage in corruption across cultures, but different usage of punishment. Subjects in India are more tolerant of bribes than in Australia (consistent with corruption norms); however, subjects in Singapore are more tolerant than subjects in Indonesia (inconsistent with corruption norms). They argue that this inconsistency arises from recent institutional changes in Indonesia designed to combat corruption. Using a similar framework,

\footnotetext{
${ }^{8}$ The discussion below does not exhaust the experimental literature on corruption. For related results on bribery see also Van Veldhuizen 2013, Armantier and Boly 2012, Abbink 2005; and for related results on embezzlement, Azfar and Nelson 2007, Barr et al. 2009. We focus here on the work most relevant to the current study.
} 
Alatas et al. (2009) show that gender differences in corruption vary by culture. In a related experimental paper, we show that implementation of punishment varies by culture: Pakistani subjects punish corrupt behavior less than Americans, and thus identical institutions designed to curb corrupt behavior produce different effects across cultures (Banuri and Eckel 2014).

Barr and Serra (2010) conduct an experiment using international students at Oxford University. They find that individuals from more corrupt societies are more likely to engage in corruption in the lab. They argue that subjects bring their social norms into the lab, and these norms impact their intrinsic motivation to engage in corrupt activities. These results are similar to Fisman and Miguel (2007), who show greater parking violations by diplomats from highcorruption countries. In related research, Bicchieri (2006) provides an excellent overview and argues that preferences for norm compliance rely on expectations about norms in the population (empirical expectations), and expectations that others will adhere to the norm (normative expectations). A norm can then be internalized (i.e. transformed into intrinsic motivation) when one attributes value in conforming to the norm absent of external inputs.

Another important area of inquiry involves the use of punishment to reduce free riding in public goods settings. Fehr and Gachter (2000) show that allowing subjects to punish noncontributors substantially reduces free riding and increases voluntary contributions to public goods. Herrmann et al. (2008) examine punishment behavior across cultures. Chaudhuri (2011) provides a review of laboratory research on punishment. It is worth noting that several studies adopt a similar design to ours, consisting of pre-punishment, punishment and post-punishment phases. Our design is most similar to Masclet et al. (2003), which examines the role of monetary vs. non-monetary punishment mechanisms in public goods games. Their main finding is that non-monetary punishment is as effective in raising contributions as monetary punishment. Most relevant for us, however, is that they find no differences in contributions in the post-punishment phase in either case, indicating the importance sustaining an intervention to enhance contributions. We find results in line with theirs.

\section{Experimental Design and Implementation}

To test the effects of a crackdown, we construct a three-player repeated bribery game with fixed partners. The three players are: a firm that makes a discrete choice of whether to offer a bribe to the government official; a government official that observes the firm's behavior and 
makes a discrete choice whether to grant the firm a favor; and a third party (citizen) who is negatively impacted by the transaction. In the baseline the citizen is passive, but in the punishment phase he can punish, at a cost, both the official and the firm. Figure 1 presents the structure of the game.

\section{[Figure 1 here]}

Note that all players begin with an initial endowment of 50 tokens; thus the initial distribution of resources is "fair." Furthermore, since engaging in corruption reduces total welfare, this starting point is also the social optimum. To offer a bribe, the firm incurs a cost of 10 tokens; this cost is incurred regardless of whether the bribe is accepted. The official can observe the offer, and can then choose to accept the bribe and provide a favor to the firm, or to reject and report the bribe. Providing a favor costs the government official 2 tokens (understood as the costs of dishonesty, similar to Abbink et al. 2002). The favor benefits the firm by 30 tokens, and hurts the citizen by 35 tokens, yielding a reduction in net welfare. Finally, the government official can provide a favor, even if a bribe has not been offered; doing so solicits a bribe by signaling to the firm his willingness to engage in bribery. This is an important aspect of the repeated game framework; officials can effectively initiate the bribery process even if the firm does not do so. ${ }^{9}$ Further note that in the baseline (without punishment) the citizen is passive, and does not have any action that impacts the earnings of the other two players. ${ }^{10}$ The Nash equilibrium of the stage game is for the firm to bribe, and the official to accept the bribe and grant a favor.

In the second phase a crackdown is implemented via a punishment institution whereby citizens can allocate up to 15 tokens to punish either the firm, or the government official, or both. The punishment technology is linear, and an expenditure of one token by the citizen reduces the earnings of the target by two tokens. Note that because punishment is costly, the Nash equilibrium of the stage game remains unchanged, where a bribe is offered and a favor provided, and punishment is zero.

\footnotetext{
${ }^{9}$ This design choice stems directly from the observation that petty corruption involves fixed relationships. Officials know that there is a distribution of clean and corrupt agents, and often have to signal their willingness to participate in bribe transactions before bribes are offered. Officials can signal their willingness by providing favors in the hopes of attracting bribes at a later date.

${ }^{10}$ For the sake of parallelism, we asked citizens to indicate a hypothetical punishment decision, so that they were also forced to pay attention and less likely to become bored.
} 
This form of "third-party punishment" is designed to capture whistle-blowing, the first step towards prosecuting corruption. It is common in developing countries that a citizen, at some cost, can take the first move in initiating a prosecution that can result in fines or imprisonment for the parties to the corrupt transaction. ${ }^{11}$ The cost of punishment reflects the short-term burden of the whistle-blower. Reporting the transaction may yield benefits, but likely only in the long run. In most countries, there is no immediate benefit to reporting a bribe, which is why amnesty programs for those who report paying a bribe have been proposed (Basu, 2011). ${ }^{12}$

Furthermore, our design allows citizens to punish firms and officials regardless of their actual behavior. This design choice was made in part for simplicity, to avoid imposing rules on citizens about when they can punish. In addition, the fixed-partners design, which reflects the repeated interaction inherent in most petty corruption, means that punishment can be effective whenever it is implemented. This mimics a situation where citizens can report and punish wrongdoing in a repeated interaction at any point. Finally, since subjects are in fixed triads and develop reputations, punishment has strategic value, even though it does not change the Nash equilibrium in monetary payoffs. ${ }^{13}$

At the beginning of the experiment subjects are told that they will engage in three tasks, and that all earnings accumulated throughout the session will be paid to them in cash at the end of the session. First is the pre-crackdown phase, which consists of ten rounds where the citizen's role is passive: his payoffs are determined by the actions of the other two payers. Second is the crackdown phase, consisting of ten rounds where the citizen is given the option to punish the other two players. While subjects know that the experiment will continue for multiple rounds, the instructions for the second phase are revealed only at the end of the first phase (and instructions for the third phase revealed only at the end of the second phase). The third, postcrackdown phase consists of ten rounds, and is identical to the first phase. A quiz is conducted

\footnotetext{
${ }^{11}$ An alternative way to model punishment is via institutional punishment (as in Abbink et al., 2002), where detection is probabilistic, and the penalty is implemented automatically (by the experimenter) conditional on detection. See Fehr and Fischbacher (2004) for an experimental study of third-party punishment across cultures.

${ }^{12}$ The current use of internet technology (for example, corruption reporting websites such as "ipaidabribe.com") is designed to reduce the costs of reporting for the citizens.

${ }^{13}$ In our model (as in the real world), bribery is risky. To overcome this, officials sometimes have relationships with specialists whose sole job is to mediate bribery transactions with citizens. An example of this is discussed in Bertrand et al. (2007), where agents exist that conduct corrupt transactions with officials in driver's license offices in India. Having fixed partners allows subjects to accurately calibrate the risks associated with bribery.
} 
after each set of instructions to gauge comprehension of the task. Since partners are fixed throughout the session, subjects are reminded of this at the beginning of each phase.

Note that we use 'loaded' language - describing the players as firm, official and citizen to increase the probability of triggering social norms; however we do not use words with an illegal connotation (such as "bribe"). Loaded language enhances subject understanding of the environment of the experiment, but avoiding stronger terms protects against negative framing that might yield experimenter demand effects.

Sessions were conducted in February and March 2010. Samples are drawn from each of two countries that vary in the overall level of corruption: In the US, 96 undergraduate students were recruited at the University of Texas at Dallas; in Pakistan, 123 undergraduate students were recruited at the Institute of Business Administration in Karachi. Table 1 describes the samples in the two locations. Game instructions are provided in the online appendix. All sessions were conducted in English. ${ }^{14}$ In each session, subjects were randomly assigned to the role of firm, government official, or citizen. The roles for each subject remained fixed throughout the session.

[Table 1 here]

In the final stage of each session, subjects were asked to complete a survey containing questions about their demographic and socioeconomic status, as well as questions relating to the experiments themselves. At the end of the session, subjects were paid their cumulative earnings, including a show up fee of \$5 in the US and PKR 100 in Pakistan. The exchange rate for tokens was \$1 USD for 100 tokens in the US and PKR 30 for every 100 tokens in Pakistan, such that for the most conservative response (no bribe, no favor and no punishment), each subject would earn $\$ 10$ USD. Payoffs were calibrated across the two countries based on the cost of two lunches at local restaurants that students at each location were known to frequent. The instructions and game were computerized using the z-Tree application developed by Fischbacher (2007).

\section{Results}

Table 2 provides a summary of the overall bribes and favors in the experiment. In the pre-crackdown phase (rounds 1 - 10), bribes are offered in the US in 72 percent of decisions, and

\footnotetext{
${ }^{14}$ At the Institute of Business Administration in Pakistan, all instruction is in English. Indeed, all schooling of these subjects would have been in English-based schools. Most students at the university sit for standardized British high school examinations ( $\mathrm{O}$ and $\mathrm{A}$ levels). English is the language of choice for business transactions at this level.
} 
in 66 percent of decisions in Pakistan (the difference is not significant: $p=0.60) .{ }^{15}$ During the crackdown, US bribes are significantly lower, dropping to approximately 33 percent, while in Pakistan they are relatively stable at 54 percent (difference between US and Pakistan in crackdown phase: $\mathrm{p}<0.10$ ). This reduction (from pre-crackdown to crackdown phase) is significantly lower in the US $(\mathrm{p}<0.01)$, but not in Pakistan $(\mathrm{p}=0.12)$. Finally, in the postcrackdown phase, US bribes rebound back to 63 percent (a 9 percent reduction from precrackdown: $\mathrm{p}=0.27$ ), while Pakistan bribes rebound back to 60 percent (a 12 percent reduction from pre-crackdown: $\mathrm{p}=0.44$ ). Post-crackdown bribes are not significantly different between the US and Pakistan $(\mathrm{p}=0.84)$.

Favors are granted in the US at a rate of 54 percent during the pre-crackdown rounds, not significantly different from 56 percent in Pakistan $(\mathrm{p}=0.87)$. During the crackdown phase, a substantial reduction in favors is observed in the US (from 54 to 16 percent, $\mathrm{p}<0.001$ ). In Pakistan, however, a relatively small reduction is observed during the crackdown (from 56 to 44 percent, $p=0.12$ ). In this phase, favors are significantly lower in the US than in Pakistan $(\mathrm{p}<0.05)$. Post crackdown, however, favors rebound for the US sample back up to 52 percent $(p=0.82)$. For the Pakistan sample, favors rebound to 47 percent $(p=0.23)$. In addition, favors in the post crackdown phase are not significantly different across cultures $(\mathrm{p}=0.67)$.

[Table 2 here]

Figure 2 illustrates the overall levels of bribes and favors across the two cultures. This figure tells the main story of the results. Pre-crackdown behavior is quite similar across the two countries, in contrast to previous studies (Cameron et al. 2009; Barr and Serra, 2010). ${ }^{16}$ During the crackdown phase, both bribes and favors fall in both countries, but the US levels are below those of Pakistan. Most importantly, regardless of what happens during the crackdown, bribery rebounds sharply at the end of the crackdown phase. These results point to the ineffectiveness of crackdowns in constraining corrupt behavior in the long run.

\footnotetext{
${ }^{15}$ Unless otherwise indicated, all non-parametric tests between the US and Pakistan are 2 sample, 2-tailed proportions tests. Non-parametric tests between phases are one-sample 2-tailed proportions tests. Since this is a repeated game, treating each decision as independent is inappropriate. Therefore, the proportions tests are conducted using each subject as a single observation, rather than each decision as a single observation.

${ }^{16}$ In the pre- and post-crackdown periods, bribery is virtually identical across the two cultures, despite major differences in corruption. There are a number of reasons why this could arise, but differences in design are likely to play a role. The experiments in Cameron et al. 2009 and Barr and Serra 2010 are one-shot, while ours are repeated (following Abbink et al. 2002). The repetition removes uncertainty associated with bribery, and population-based beliefs about others' behavior play a limited role. Further study is needed to disentangle possible causes.
} 
[Figure 2 here]

\subsection{Pre- and Post-Crackdown Comparison of Bribes and Favors}

Next, we turn to the main question of our study: comparing behavior in the precrackdown and post crackdown phases with each other. We observed that the beginning of the post-crackdown phase shows a large break with the overall trend in the experiment. We turn our attention to whether corruption increases or decreases once punishment institutions are removed (in the post-crackdown era).

Figure 3 presents bribe frequencies and compares behavior in the post-crackdown phase with behavior in the pre-crackdown phase for the US (top left) and Pakistan (top right). Figure 3 also presents favor frequencies in the pre- and post-crackdown phases for the US (bottom left) and Pakistan (bottom right). What is striking in these figures is that the overall trend in bribes and favors is virtually identical between the phases.

[Figure 3 here]

To formally test differences between pre- and post-crackdown bribes and favors, we estimate random-effects probit models on the probability of offering a bribe in the US and Pakistan separately. ${ }^{17}$ We regress the dummy variable for offering a bribe (equaling 1 if a bribe was offered) on dummy variables for the crackdown and post-crackdown phases. We use the round number (from 1 to 10 ) to account for the trend in each phase separately. ${ }^{18}$ We also control for basic demographic information (gender and age). Estimation results are shown in table 3: model 1 reports the results for the US, while model 2 does the same for Pakistan. ${ }^{19}$ If bribery responds purely to incentives, then we should observe no difference in the post-crackdown phase relative to the pre-crackdown phase. However, if intrinsic motives to abstain from corruption are important, then the post-crackdown phase could be affected by the crackdown. If such motives are crowded out, then we should observe an increase in bribery in the post-crackdown phase;

\footnotetext{
${ }^{17}$ Estimates are robust to using fixed effects logit models (not shown).

${ }^{18}$ We use the round numbers for each phase separately so as to compare the intercepts and slopes from the postcrackdown phase to the intercept and slope in the pre-crackdown phase directly. The online appendix presents the alternate specification under the assumption of a common trend with structural breaks. We are grateful to an anonymous referee for pointing out this alternate specification.

${ }^{19}$ Results are robust to controlling for history within the triad (i.e. a variable indicating whether a favor was granted in the previous round). This is excluded from the table due to endogeneity concerns. Adding additional lags (beyond a single period) also does not alter our results.
} 
alternatively, if punishment signals a new norm, then we should observe a reduction in bribes in the post-crackdown phase.

[Table 3 here]

The regression results confirm what we observe in the figures. In the post-crackdown phase, bribe behavior is not significantly different from the pre-crackdown phase, either in the US ( $p=0.34)$, or in Pakistan $(p=0.81)$. During the Crackdown phase, however, bribes are significantly lower than in the pre-crackdown phase by about $44 \%$ overall $(\mathrm{p}<0.01)$. This is not true for Pakistan, however, where we observe an overall decline of just $6 \%(p=0.50)$. In the US, the probability of offering a bribe declines over time at a rate of $3.8 \%$ per round $(\mathrm{p}<0.01),{ }^{20}$ and is not significantly different in either the crackdown or post-crackdown phases $(p=0.23$ and $\mathrm{p}=0.74$ respectively). ${ }^{21}$ In Pakistan, the probability of offering a bribe declines at a rate of $0.88 \%$ per round, but it is not significantly different from zero $(\mathrm{p}=0.39)$. Further, the probability is not significantly different in the crackdown and post-crackdown phases $(p=0.14$ and $p=0.20$ respectively).

Favors also display a virtually identical pattern to bribes. Table 3 reports favor results for the US and Pakistan, using the same model specification as above, focusing on government official behavior. Again, both in the US $(p=0.31)$ and Pakistan $(p=0.26)$, post-crackdown probability of providing a favor is not significantly different from the pre-crackdown probability overall. We observe a significant reduction in the probability in the crackdown phase for the US (a reduction of $45 \% ; \mathrm{p}<0.01$ ), but not for Pakistan $(\mathrm{p}=0.32$ ). In the US, favor probability declines over time at the rate of $4.1 \%$ per round $(p<0.01)$, and does not significantly differ for the crackdown and post-crackdown rounds ( $p=0.73$ and $p=0.50$ respectively). In Pakistan, the

\footnotetext{
${ }^{20}$ Changes in probability were calculated using marginal effects (not reported).

${ }^{21}$ What would explain the reduction in the probability of offering a bribe or favor over time in the US? This is a surprising result that has not been found in previous research. Abbink and coauthors $(2002,2004,2006)$ have conducted repeated versions of bribery games, with no decline. However, a key difference between our design and theirs lies in the target of the externality. Under their framework, the negative externality of corruption is imposed on all other players of the game, and indeed, each firm/official dyad is subject to externalities generated from other players of the game. Our design implements a single target of the negative externality, which increases the salience of the externality for the subjects. Moral costs rise with cumulative externalities, and with higher moral costs, subjects find it more costly and difficult to engage in corruption. In Table A1 in the online appendix, we provide some evidence for this, as each successful bribe reduces the likelihood of a favor by $7 \%$ in the first ten rounds $(p<0.05)$. We can speculate that the moral costs are more salient for the government officials (since they have the choice directly impacting the externality), and hence why the effect is observed for the favors, and not for bribes. This is suggestive evidence, as our data does not allow us to completely explore the nature of the decline. In addition, it is also not clear why culture would have a differential impact on the salience (we do not observe this downward decline in Pakistan). In the appendix we then argue that this decline may be something of an illusion, as it is not observed in a similar experiment without a "crackdown" regime change in period 11.
} 
probability of providing a favor is also declining, but it is not significant overall $(\mathrm{p}=0.59)$, or in the crackdown and post-crackdown phases $(\mathrm{p}=0.25$ and $\mathrm{p}=0.64$ respectively).

One aspect of this analysis is to test the effectiveness of crackdowns across the two settings. In order to do this, we pool the US and Pakistan samples and estimate random-effects probit models on the probability of offering a bribe (model 1) and the probability of providing a favor (model 2), for just the pre- and post-crackdown phases. ${ }^{22}$ We add Pakistan interaction terms for the intercepts and slopes of the pre- and post-crackdown phases. Thus, as before, we directly compare behavior in the pre- and post-crackdown phases, but across cultures. We regress the dummy variable for offering a bribe (equaling 1 if a bribe was offered) on a dummy variable for the post-crackdown phase. We use the round number (from 1 to 10) to account for the trend in each phase separately, and interact a dummy variable for Pakistan with each of the variables above. We also control for basic demographic information (gender and age). The results are presented in table 4. Crucially, we see that the pre-post crackdown differences in intercepts and slopes are not significantly different between the two countries (intercept difference-in-difference: $\mathrm{p}=0.33$; slope difference-in-difference: $\mathrm{p}=0.85$ ).

These results confirm the incentives hypothesis, that crackdowns are ineffective in sustaining reductions in bribery regardless of intrinsic motives or norms. There are a few interesting differences, however. First, the initial probability of offering a bribe is significantly higher in the US than in Pakistan $(\mathrm{p}<0.10)$. However, while the probability of a bribe significantly decreases over time in the US, it significantly increases in Pakistan, relative to the US ( $<<0.05)$, and is relatively stable overall (i.e. not significantly different from zero: $p=0.40$ ). This higher initial probability of bribe offers is puzzling since overall levels of corruption in Pakistan are greater than in the US. Our data do not allow us to address this question.

\section{[Table 4 here]}

Overall, the results show an interesting pattern. First, in the US, the crackdown appears to have an immediate effect on bribes and favors. In addition to this, we observe sharp rebounds in bribe and favor behavior once the crackdown is removed. In Pakistan neither the trend, nor the crackdown, point to a reduction in bribes or favors. These results indicate that once the crackdown is alleviated, subjects return to the pre-crackdown levels of bribes and favors.

\footnotetext{
${ }^{22}$ Since we are primarily interested in a direct comparison of the pre- and post-crackdown phases, the regression drops the crackdown phase.
} 


\subsection{Crackdown Impact: Punishment, Bribes and Favors}

Despite the fact that punishment is costly to the punisher, we see a considerable amount of punishment in the experiment in both countries. Punishment behavior during the crackdown phase across the two countries is described in figure 4, which shows average differences in punishment between countries for four possible combinations of bribes and favors. The figure contains the difference in punishment expenditure between US and Pakistani subjects, and shows that while punishment of firms is not significantly different between the two countries, subjects in Pakistan punish government officials at significantly lower levels when favors have occurred. ${ }^{23}$ Punishment of government officials is lower in Pakistan when a favor has been granted, indicating that officials are less likely to be held responsible for their corrupt behavior.

[Figure 4 here]

In addition, figure 5 presents expenditure on firm and official punishment separately for the US and Pakistan and shows that punishment declines over time during the crackdown phase as firms and officials reduce their corrupt practices.

[Figure 5 here]

During the crackdown phase, punishment directly and indirectly affects corrupt behavior, and contributes to the impact of the crackdown. ${ }^{24}$ To test the effectiveness of both direct and indirect punishment, we conduct random effects OLS regressions on the change in bribes and favors (from round $\mathrm{t}-1$ to round $\mathrm{t}$ ) on punishment spending by the citizen in the previous round. To test for cross-cultural differences in responsiveness to punishment, we add variables for Pakistan (dummy variable equaling 1 if the subject is located in Pakistan) and interactions terms of culture with previous punishment behavior. The results are presented in Table 5.

[Table 5 here]

This table shows that firm punishment in the previous round has a negative and significant impact on the change in bribing behavior across rounds, with firms less likely to offer a bribe as a response. Similarly, tokens spent punishing the official also yield changes in

\footnotetext{
${ }^{23}$ One exception to the difference in firm punishment is that Pakistani subjects punish firms approximately 1.5 tokens more than US subjects when a bribe is offered, but not accepted by the official. While we have little evidence of why this occurs, we conjecture that this may be due to differences in how subjects perceive the confiscation of the bribe. US subjects may view the confiscation as punishment, while Pakistanis may not view that as punishment, and feel the need to further reprimand the firms.

${ }^{24} \mathrm{We}$ are grateful to an anonymous referee for pointing this out.
} 
behavior: official punishment in the previous round has a negative and significant impact on the change in favor provision, with officials less likely to provide favors. Interestingly, tokens spent on firm punishment also lead to a change in favor provision, independent of official punishment; providing an indirect effect through reduced bribing. Importantly, however, while higher spending on punishment significantly reduces the propensity to engage in bribes/favors in subsequent rounds, this propensity does not vary by culture. That is, Pakistani firms/officials are no more or less sensitive to punishment than US firms/officials (as noted by the insignificant coefficients on the interaction terms in the table). Responsiveness to punishment does not vary by culture. Therefore, the main reason for the differential impact of punishment institutions across cultures (replicating findings from Banuri and Eckel, 2014) is that Pakistanis punish officials significantly less than in the US. Punishment of officials yields a reduction in favors, and subsequently, a reduction in bribes.

Overall, we find stark rebounds of both bribes and favors in the US and Pakistan, which indicates that subjects largely return to similar levels of bribery post-crackdown. This suggests that engaging in bribery (at least in the time horizon of our experiment) is determined largely by incentives, and that intrinsic motives (through cumulative moral costs) may play a role in reducing the likelihood of engaging in bribes, but these motives do not respond to crackdowns. We conclude that temporary policy interventions do not alter bribes in the long run. Importantly, however, a temporary regime shift does not exacerbate the corruption problem. This indicates that, while crackdowns may not have a lasting positive impact, they may not have detrimental impacts either.

\section{Conclusion}

We address the question of how crackdowns on bribery might interact with social norms to exacerbate the corruption problem. We implement corruption norms by drawing samples from two countries with very different societal levels of corruption. Our results indicate that bribery is largely affected by extrinsic incentives - direct financial consequences. Crackdowns (i.e. punishment institutions) can be implemented in a way to shift incentives away from corrupt behavior, but need to be sustained in order to have a long-term impact. Without enforcement, we find that bribery returns back to pre-crackdown levels. Furthermore, the difference between preand post-crackdown behavior does not vary by culture, meaning that intrinsic motives have little 
impact in a repeated game framework. As a matter of policy, our results underline the need for sustainable policy tools to combat corruption. Proponents of corruption crackdowns may argue that each intervention changes corruption norms in subtle ways, and that repeated crackdowns may eventually yield differences in overall corruption levels. We find very little evidence of any impact of motives and norms.

One potential factor that our study cannot address is the effect crackdowns have on selection. As a reviewer correctly points out, crackdowns may remove the outliers from the corrupt pool, leaving the relatively "cleaner" individuals, and thus a relatively "cleaner" system. These are testable ideas, but outside the scope of this paper. These selection issues are interesting areas for future research.

Overall, these results are good news for policy-makers. First, if these lab results extend to the field, they suggest that different anti-bribery policies can be tested in a field setting without worrying about lasting negative effects. They also suggest that repeated crackdowns are not likely to exacerbate the corruption problem. However, the results underline the importance of sustainable institutions in reducing bribery. A key feature of this study is that it identifies the effects of a temporary, unsustained policy, which (to our knowledge) has not been addressed in the literature.

Our results find that corruption norms may be purely incentive-driven, and not based on ingrained values. From a policy standpoint, this suggests that not only can we trial different policy mechanisms without lasting effects, but also that individuals are not intrinsically motivated to bribe, but rather respond to expectations and extrinsic factors. This lends credence to the economist's view of the importance of extrinsic motives in corruption settings. In effect, this provides some good news in that corruption can be combated as long as institutional constraints are addressed. 


\section{Acknowledgements}

We are indebted to Klaus Abbink, Rachel Croson, Reuben Kline, Sherry Xin Li, Angela de Oliveira, Elizabeth Pickett, Wendy Mak, Eric McLester, Quoc Tran, participants of the Economic Science Association meetings in Tucson, AZ, and participants of the workshop on conflict experiments in Rennes, FR. The paper was substantially improved during the editorial process. Funding was provided by the National Science Foundation (NSF SES-0921884). Any errors remain our own. 


\section{References}

Abbink K (2004) Staff rotation as an anti-corruption policy: an experimental study. Europ J Polit Economy 20:887-906

Abbink K (2005) Fair salaries and the moral costs of corruption. In: Kokinov B (ed) Advances in Cogntive Economics. NBU, Bulgaria

Abbink K, Hennig-Schmidt H (2006) Neutral versus loaded instructions in a bribery experiment. Exper Econ 9:103-121

Abbink K, Irlenbusch B, Renner E (2002) An experimental bribery game. J Law Econ Organ 18:428-454

Abbink K, Serra D (2012) Anticorruption policies: Lessons from the lab. Research in Experimental Economics 15:77-115

Alatas V, Cameron L, Chaudhuri A, Erkal N, Gangadharan L (2009) Gender, culture, and corruption: Insights from an experimental analysis. Southern Econ J 75:663-680

Armantier O, Boly A (2012) On the external validity of laboratory experiments on corruption. Research in Experimental Economics 15:117-144

Azfar O, Nelson Jr W (2007) Transparency, wages, and the separation of powers: An experimental analysis of corruption. Public Choice, 130:471-493

Banuri S, Eckel C (2012) Experiments in culture and corruption: A review. In: Serra D, Wantchekon L (eds.) New Advances in Experimental Research on Corruption 15. Emerald Group, New York, pp. 51-76

Banuri S, Eckel C (2014) The Effects of Sanctions on Bribery: US Versus Pakistan. Working Paper, Texas A\&M University

Bardhan P (2006) The economist's approach to the problem of corruption. World Devel 34:341-348

Barr A, Lindelow M, Serneels P (2009) Corruption in public service delivery: An experimental analysis. J Econ Behav Organ 72:225-239

Barr A, Serra D (2010) Corruption and culture: An experimental analysis. J Public Econ 94:862-869

Basu K (2011) Why, for a class of bribes, the act of giving a bribe should be treated as legal. India Ministry of Finance Report

Becker G (1968) Crime and punishment: An economic approach. J Polit Economy 76:169-217

Bertrand M, Djankov S, Hanna R, Mullainathan S (2007) Obtaining a driver's license in India: an experimental approach to studying corruption. Quart J Econ 122:1639-1676

Bicchieri C (2006) The Grammar of Society: The Nature and Dynamics of Social Norms. Cambridge: Cambridge University Press

Bicchieri C, Muldoon R (2011) Social norms. In: Zalta E (ed) The Stanford Encyclopedia of Philosophy, 2011 edn. Stanford, California

Brinkerhoff D, Kulibaba N (1996) Perspectives on participation in economic policy reform in Africa. Studies in Comparative International Development 31:123-151

Buckley C (2013) With Official's Conviction, China Calls Attention to Its Crackdown on Corruption. New York Times. http://www.nytimes.com/2013/09/23/world/asia/with-officials-convictionchina-calls-attention-to-graft-crackdown.html. Accessed 18 December 2013

Cameron L, Chaudhuri A, Erkal N, Gangadharan L (2009) Propensities to engage in and punish corrupt behavior: Experimental evidence from Australia, India, Indonesia and Singapore. J Public Econ 93:843-851 
Chaudhuri A (2011) Sustaining cooperation in laboratory public goods experiments: a selective survey of the literature. Exper Econ 14:47-83

Deci E, Koestner R, Ryan R (1999) A meta-analytic review of experiments examining the effects of extrinsic rewards on intrinsic motivation. Psychological Bulletin 125:627-668

Di Tella R, Schargrodsky E (2003) The role of wages and auditing during a crackdown on corruption in the city of Buenos Aires. J Law Econ 46:269-292

Dininio P (2005) The risks of recorruption. In: Spector B (ed.) Fighting Corruption in Developing Countries: Strategies and Analysis. Kumariain, Colorado

Fehr E, Fischbacher U (2004) Third party punishment and social norms. Evolution and Human Behavior 25:63-87

Fehr E, Gachter S (2000) Cooperation and punishment in public goods experiments. Amer Econ Rev 90:980-994

Fischbacher U (2007) Z-tree: Zürich toolbox for readymade economic experiments. Exper Econ 10:171178

Fisman R, Miguel E (2007) Corruption, norms, and legal enforcement: Evidence from diplomatic parking tickets. J Polit Economy 115:1020-1048

Frey B, Jegen R (2001) Motivation crowding theory: A survey of empirical evidence. J Econ Surveys 15:589-611

Gneezy U, List J (2006) Putting behavioral economics to work: Testing for gift exchange in labor markets using field experiments. Econometrica 74:1365-1384

Gneezy U, Meier S, Rey-Biel P (2011) When and why incentives (don't) work to modify behavior. J Econ Perspect 25:191-209

Gneezy U, Rustichini A (2000) A fine is a price. J Legal Stud 29:1-17

Hauk E, Saez-Marti M (2002) On the cultural transmission of corruption. J Econ Theory 107:311-335

Herrmann B, Thoni C, Gachter S (2008) Antisocial punishment across societies. Science 319:1362-1367. doi: $10.1126 /$ science. 1153808

Jain A (2001) Corruption: a review. J Econ Surveys 15:71-121

Kaufmann D, Kraay A, Mastruzzi M (2005) Governance matters IV: governance indicators for 19962004. World bank policy research working paper 3630

Kpundeh S (1999) The fight against corruption in Sierra Leone. In: Stapenhurst R, Kpundeh S (eds) Curbing Corruption: Toward a Model for Building National Integrity. World Bank, District of Columbia, pp. 207-234

Licht A, Goldschmidt C, Schwartz S (2007) Culture rules: The foundations of the rule of law and other norms of governance. J Compar Econ 35:659-688

Liu A (1983) The politics of corruption in the People's Republic of China. Amer Polit Sci Rev 77:602623

Masclet D, Noussair C, Tucker S, Villeval M (2003) Monetary and non-monetary punishment in the voluntary contributions mechanism. Amer Econ Rev 93:366-380

Ryan R, Deci E (2000) Intrinsic and extrinsic motivations: Classic definitions and new directions. Contemporary educational psychology 25:54-67

Tirole J (1996) A theory of collective reputations (with applications to the persistence of corruption and to firm quality). Rev Econ Stud 63:1-22

Transparency International. (2011) Corruption Perceptions Index. http://www.transparency.org. Accessed 22 August 2012 
Treisman D (2007) What have we learned about the causes of corruption from ten years of cross-national empirical research? Annual Review of Political Science 10:211-244

Van Veldhuizen R (2013) The influence of wages on public officials' corruptibility: A laboratory investigation. J Econ Psych 39:341-356 


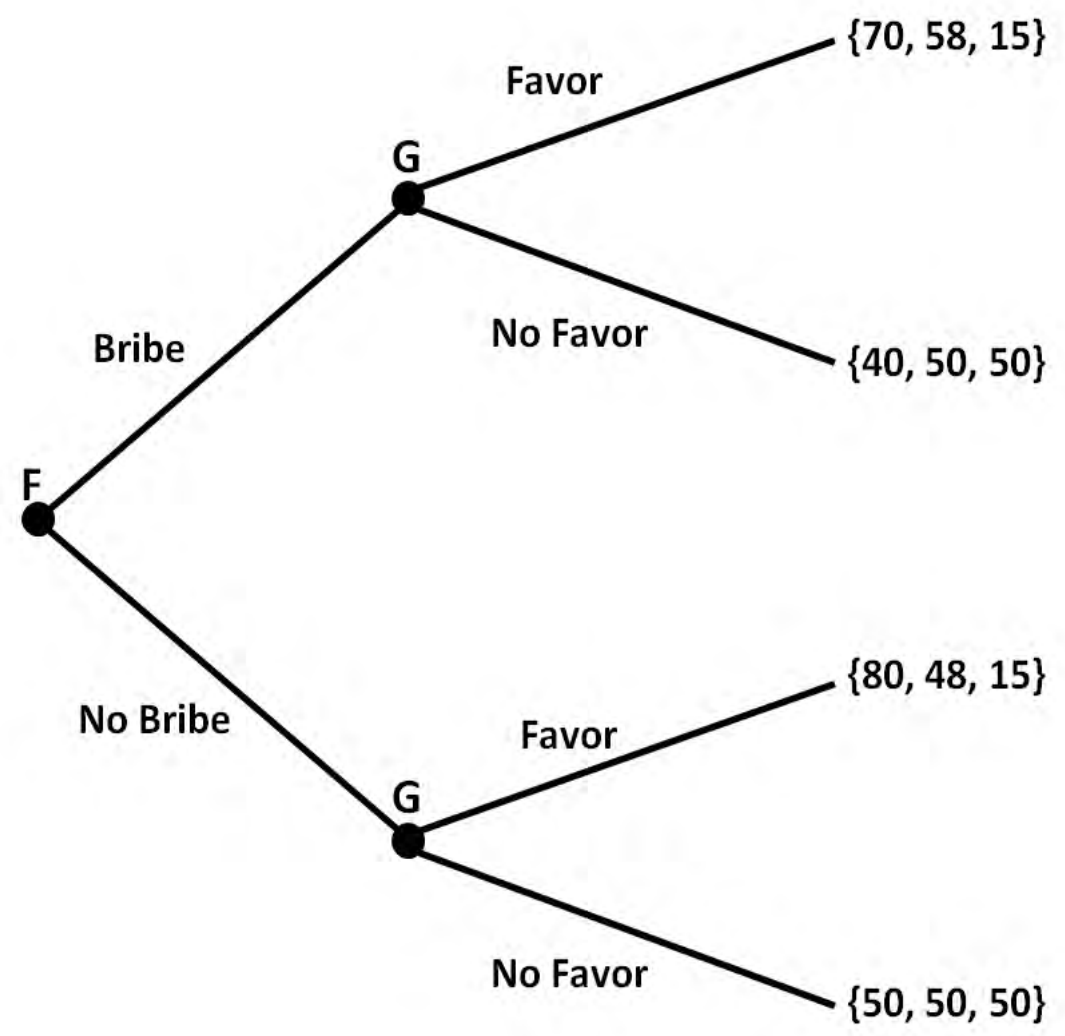

Fig. 1 Bribery game tree for the pre-crackdown and post-crackdown periods 


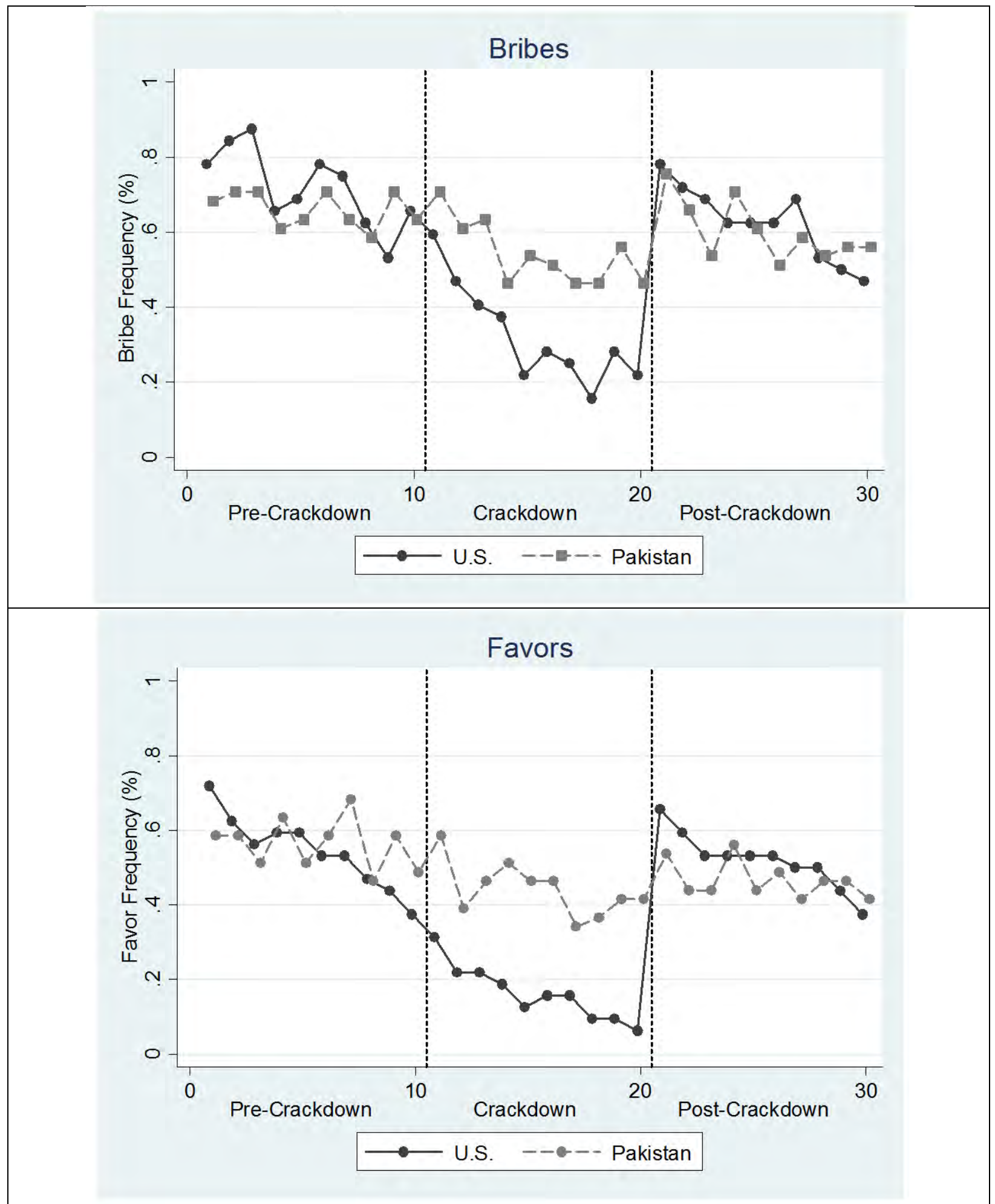

Fig. 2 Short and long run effects of punishment on bribes (top) and favors (bottom) across cultures 


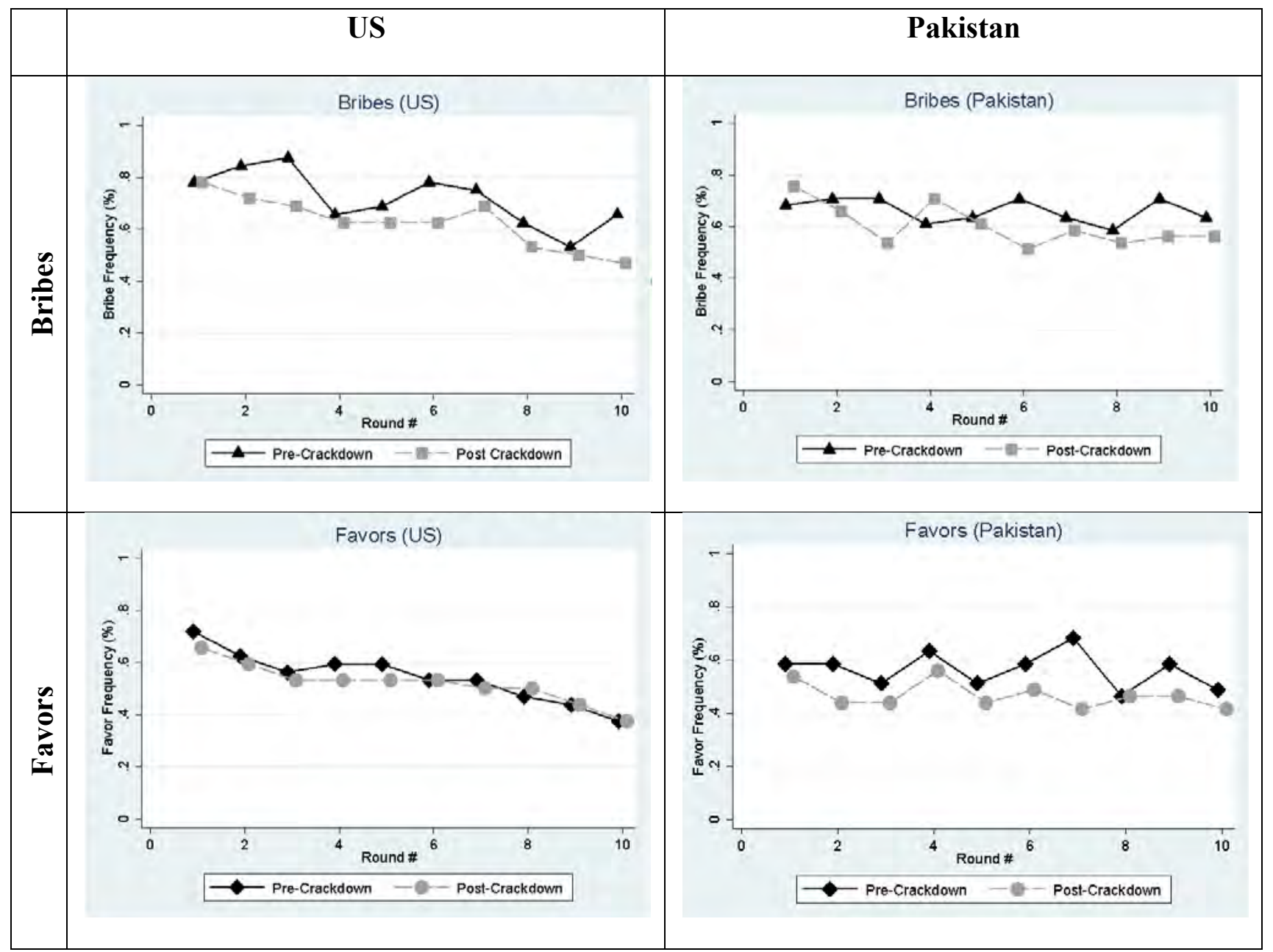

Fig. 3 Pre-crackdown and post-crackdown bribe and favor frequency for US and Pakistani subjects. Graphs compare behavior in pre-crackdown phase to the post-crackdown phase. 


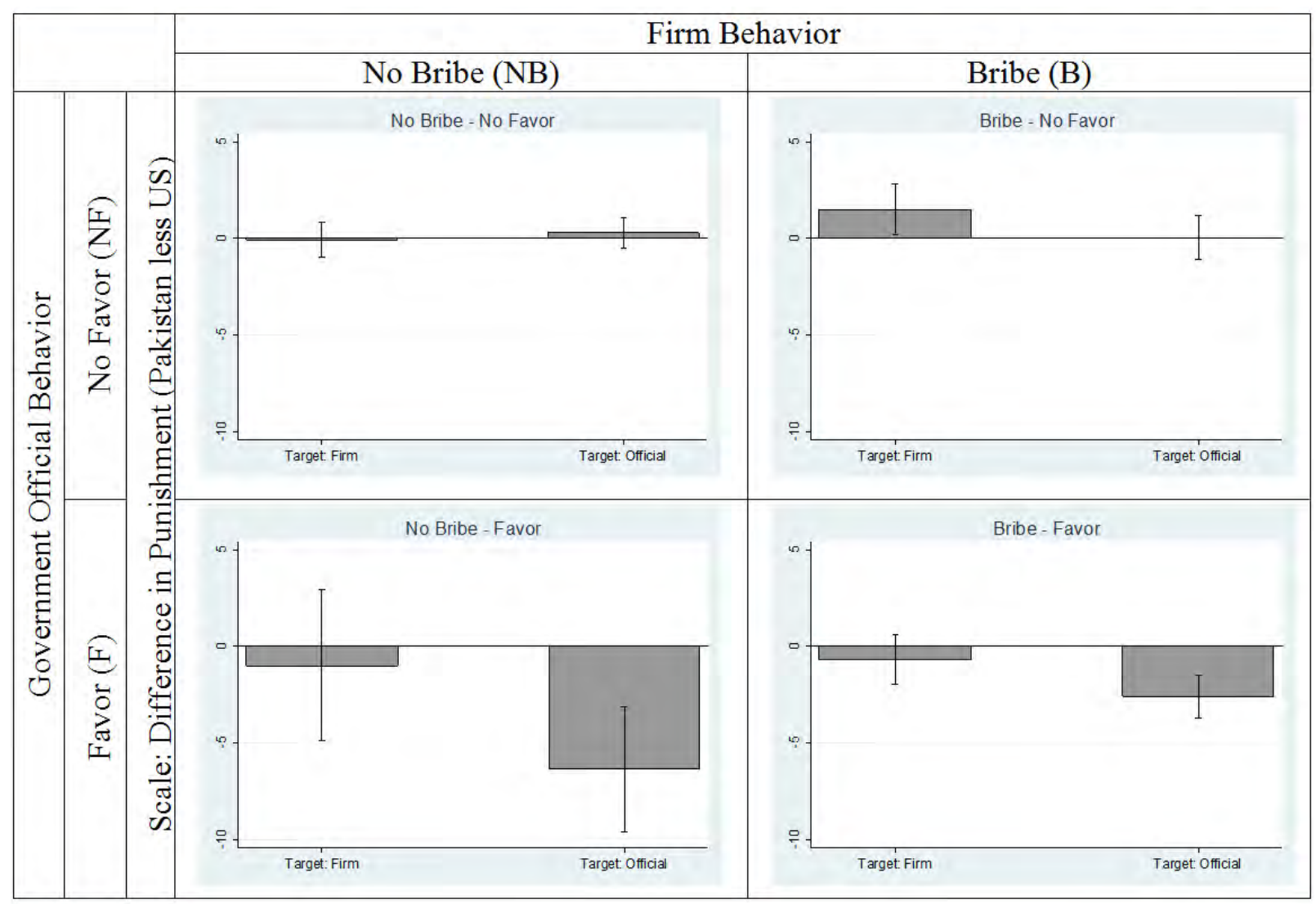

Fig. 4 Cross cultural differences in tokens allocated to punishment. Figures report differences between Pakistan and the US. Punishment differences computed from models 1 and 3 in Table A2 in the online appendix. 


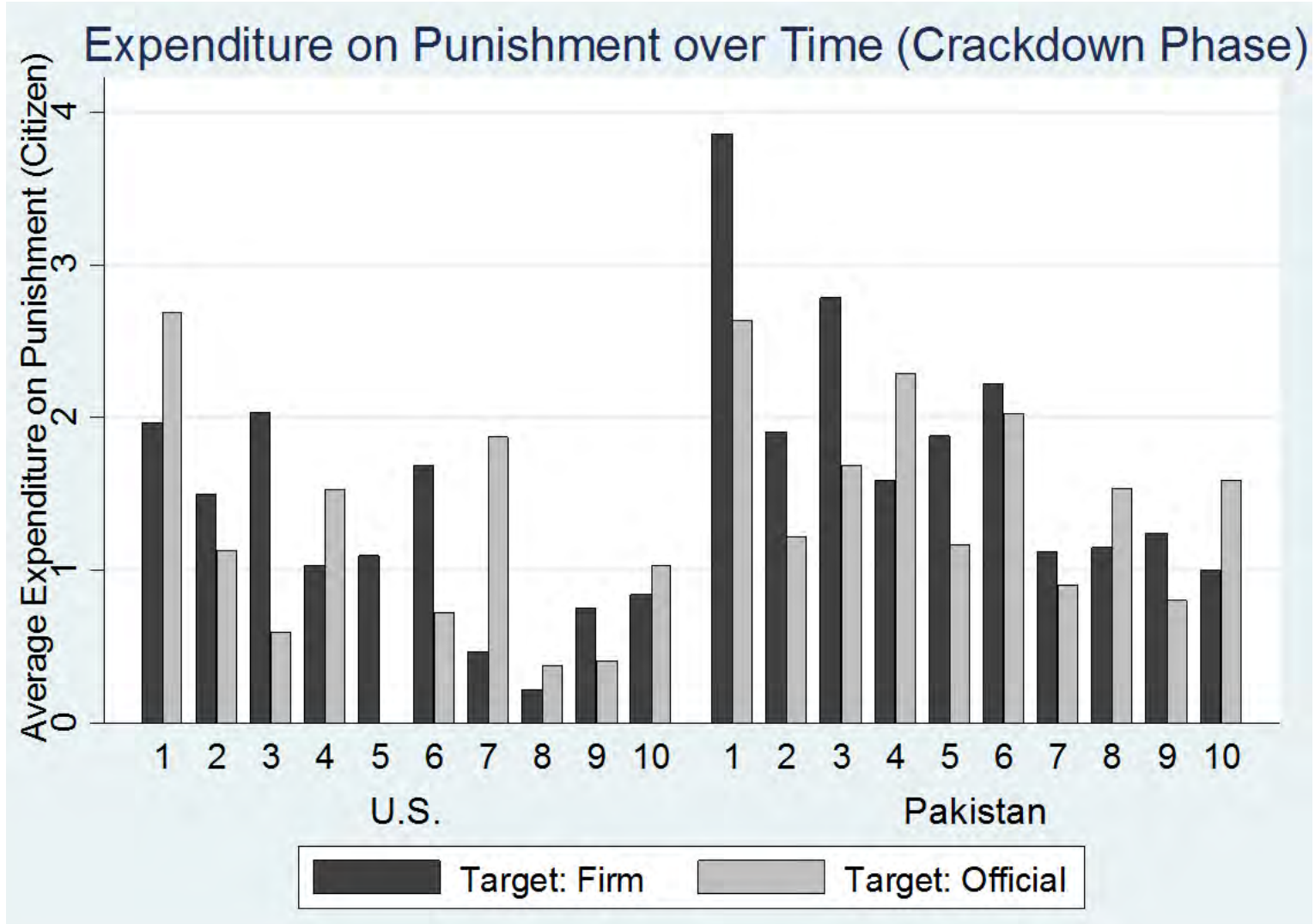

Fig. 5 Citizen expenditure (in tokens) on punishment over time during the crackdown phase 
Table 1 Sample descriptive statistics

\begin{tabular}{|lrr|}
\hline Variable & $\mathrm{US}$ & Pakistan \\
\hline Demographics, \% of sample & $\mathrm{N}=96$ & $\mathrm{~N}=123$ \\
$\quad$ Female & & \\
Average Age, years & $40 \%$ & $27 \%$ \\
Personal Finances (4 = Poor) & 20.73 & 20.65 \\
Family Income (5 = Much Above Average) & 2.60 & 2.61 \\
Religious Attendance, 1+ per week (>1 per week) & 2.69 & 3.00 \\
Part Time Student & $28 \%(9 \%)$ & $44 \%(22 \%)$ \\
Employed (Full or Part-time) & $5 \%$ & $0 \%$ \\
Cohort, \% of sample & $43 \%$ & $13 \%$ \\
Freshmen & & \\
Sophomore & $3 \%$ & $0 \%$ \\
Junior & $2 \%$ & $22 \%$ \\
Senior & $32 \%$ & $15 \%$ \\
Graduate Student & $28 \%$ & $40 \%$ \\
Not a Student & $28 \%$ & $17 \%$ \\
Major, \% of sample & $6 \%$ & $5 \%$ \\
Business / Economics & & \\
Sciences & $25 \%$ & $78 \%$ \\
Arts / Other & $70 \%$ & $40 \%$ \\
Other & $10 \%$ & $3 \%$ \\
Born in Corrupt Country & & \\
Future Corruption Expectations (5 = Optimistic) & $21 \%$ & $97 \%$ \\
Government Action against Corruption (5 Ineffective) & 2.36 & 2.02 \\
& 3.31 & 4.30 \\
\hline
\end{tabular}


Table 2 Overall bribe and favor outcomes

\begin{tabular}{|cccc|}
\hline & $\begin{array}{r}\text { Bribe Frequency } \\
\text { Pre-Crackdown Phase }\end{array}$ & Crackdown Phase & Post-Crackdown Phase \\
\hline & US & \\
Frequency & $72 \%$ & $33 \%$ & $63 \%$ \\
Frequency & -- & $\mathbf{- 3 9 \% * * *}$ & $\mathbf{- 9 \%}$ \\
\hline Difference from Pre-Crackdown & Pakistan & \\
\hline & $66 \%$ & $54 \%$ & $60 \%$ \\
Difference from Pre-Crackdown & -- & $\mathbf{- 1 2 \%}$ & $\mathbf{- 6 \%}$ \\
\hline Difference across Culture (US less PK) & $6 \%$ & $-21 \% *$ & $3 \%$ \\
\hline
\end{tabular}

\begin{tabular}{|cccc|}
\hline & $\begin{array}{r}\text { Favor Frequency } \\
\text { Pre-Crackdown Phase }\end{array}$ & Crackdown Phase & Post-Crackdown Phase \\
\hline & US & & \\
Frequency & $54 \%$ & $16 \%$ & $52 \%$ \\
Difference from Pre-Crackdown & -- & $\mathbf{- 3 8 \%} \% * *$ & $\mathbf{- 2 \%}$ \\
\hline & Pakistan & & \\
& $56 \%$ & $44 \%$ & $47 \%$ \\
Fifference from Pre-Crackdown & -- & $\mathbf{- 1 2 \%}$ & $\mathbf{- 9 \%}$ \\
\hline Difference across Culture (US less PK) & $-2 \%$ & $-28 \% * *$ & $5 \%$ \\
\hline
\end{tabular}

$* p<0.1, * * p<0.05, * * * p<0.01$

${ }^{a}$ The percentages are calculated based on the number of bribes/favors provided in each country, divided by the total rounds where bribes and favors were possible.

${ }^{\mathrm{b}}$ Statistics tests between phases are one-sample 2-tailed proportions tests, and between the US and Pakistan are 2 sample, 2-tailed proportions tests. Since this is a repeated game, treating each decision as independent is inappropriate. Therefore, the proportions tests are conducted using each subject as a single observation, rather than each decision as a single observation. 
Table 3 Regression results for bribe and favor activity in the US and Pakistan

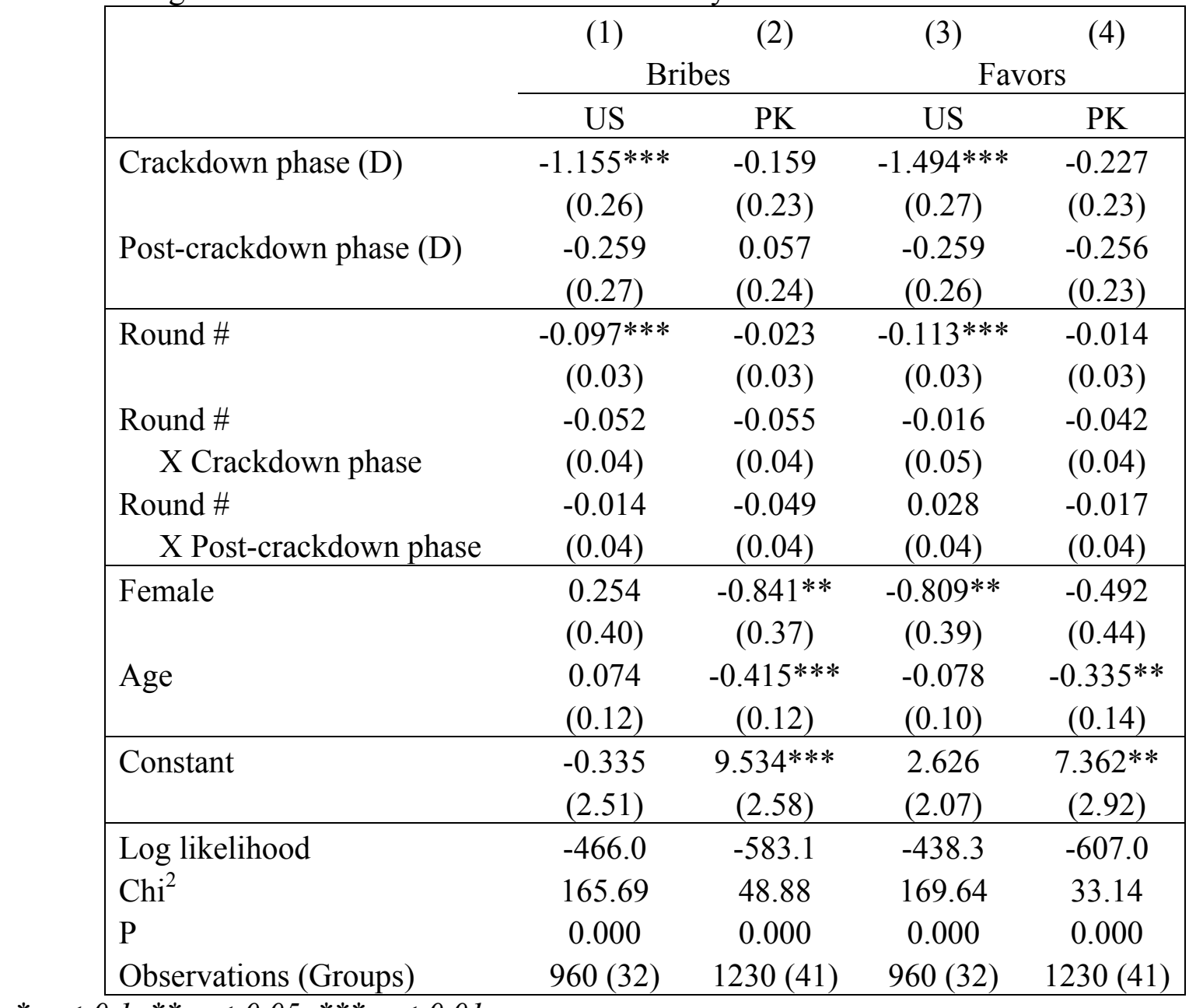

$* p<0.1, * * p<0.05, * * * p<0.01$

${ }^{a}$ Random effects Probit regression estimates. Table reports marginal effects with group-level clustered standard errors in parentheses.

b For models 1 and 2, the dependent variable takes on a value of 1 if the firm offered a bribe and 0 otherwise. For models 3 and 4, the dependent variable takes on a value of 1 if the government official provided a favor, and 0 otherwise. Models 1 and 3 are for US subjects, while models 2 and 4 are for Pakistan. 
Table 4: Regression results for culture interactions with pooled data

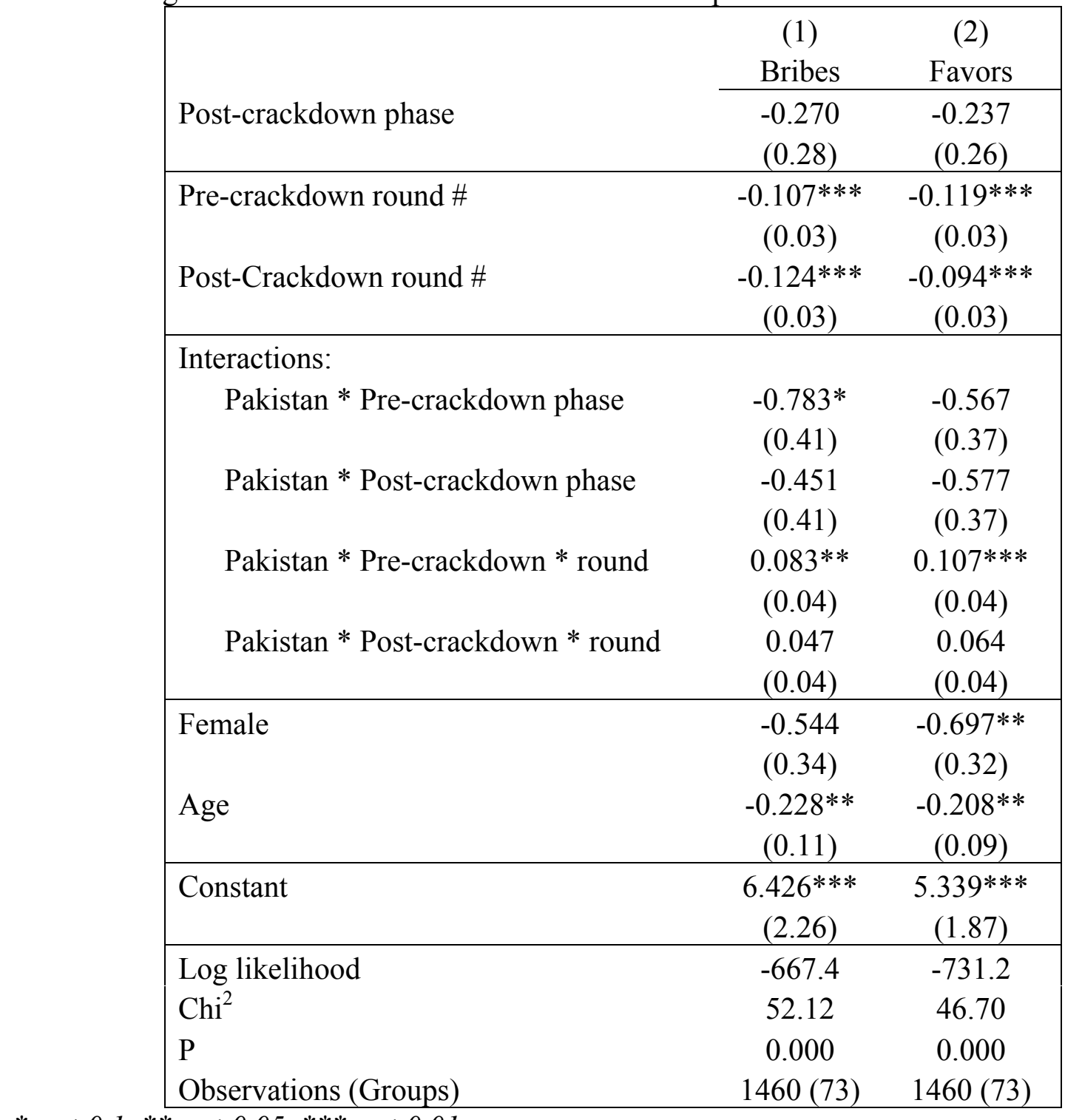

$* p<0.1, * * p<0.05, * * * p<0.01$

${ }^{a}$ Random effects probit estimates. Table reports coefficients with group-level clustered standard errors in parentheses.

${ }^{\mathrm{b}}$ For model 1 the dependent variable takes on a value of 1 if the firm offered a bribe and 0 otherwise. For model 2, the dependent variable takes on a value of 1 if the government official provided a favor and 0 otherwise. 
Table 5 Regression results for changes in bribes and favors during the crackdown phase

\begin{tabular}{|lcc|}
\hline & $(1)$ & $(2)$ \\
\cline { 2 - 3 } & $\begin{array}{c}\text { Change in } \\
\text { Bribes }\end{array}$ & $\begin{array}{c}\text { Change in } \\
\text { Favors }\end{array}$ \\
\hline Round \# & 0.003 & -0.004 \\
& $(0.01)$ & $(0.01)$ \\
\hline Firm punishment $\quad-0.019^{* *}$ & $-0.024^{* * *}$ \\
(previous round) & $(0.01)$ & $(0.01)$ \\
Government official punishment & -0.010 & $-0.054^{* * *}$ \\
$\quad$ previous round) & $(0.01)$ & $(0.01)$ \\
\hline Pakistan & 0.045 & 0.021 \\
& $(0.05)$ & $(0.04)$ \\
\hline Interactions: & & \\
Pakistan * Firm punishment & -0.017 & 0.007 \\
$\quad$ previous round) & $(0.01)$ & $(0.01)$ \\
Pakistan * Government official punishment & 0.016 & 0.010 \\
$\quad$ previous round) & $(0.01)$ & $(0.01)$ \\
\hline Female & 0.007 & -0.058 \\
& $(0.04)$ & $(0.04)$ \\
Age & 0.005 & 0.004 \\
& $(0.01)$ & $(0.01)$ \\
\hline Constant & -0.130 & 0.015 \\
& $(0.29)$ & $(0.21)$ \\
\hline Within $\mathrm{R}^{2}$ & 0.059 & 0.208 \\
Between $\mathrm{R}^{2}$ & 0.011 & 0.086 \\
Overall ${ }^{2}$ & 0.046 & 0.159 \\
P & 0.000 & 0.000 \\
Observations (Groups) & $657(73)$ & $657(73)$ \\
\hline
\end{tabular}

$* p<0.1, * * p<0.05, * * * p<0.01$

${ }^{a}$ Random effects OLS regressions. Table reports coefficients with group-level clustered standard errors in parentheses.

b Dependent variable for model 1 is the change in bribing from the previous round (t-1) to the current round $(\mathrm{t})$. Hence the variable takes on a value of 0 if no change in behavior is observed; 1 if subject bribed in the previous round but did not in this round; and +1 if subject did not bribe in the previous round but bribed in this round. Dependent variable for model 2 is the change in favors from the previous round ( $t-1)$ to the current round $(t)$. 
Online Appendix:

Cracking Down on Bribery, Social Choice and Welfare

Sheheryar Banuri and Catherine C. Eckel

Corresponding Author: Sheheryar Banuri; sbanuri@gmail.com; Development Economics

Research Group, World Bank, 1818 H St NW, MC 3-356, Washington, DC, 20433; Tel: 210394-5515; Fax: 202-522-4881

Appendix 1: Additional analysis.

Table A1 Regression results for bribes and favors in the pre-crackdown phase

\begin{tabular}{|lcccc|}
\hline & $(1)$ & $(2)$ & $(3)$ & $(4)$ \\
& \multicolumn{2}{c}{ Bribes } & \multicolumn{2}{c|}{ Favors } \\
& US & PK & US & PK \\
\hline Round \# & $-0.196^{*}$ & 0.057 & 0.112 & 0.007 \\
& $(0.12)$ & $(0.10)$ & $(0.13)$ & $(0.09)$ \\
\hline Favor (previous round) & 0.553 & 0.243 & & \\
Bribe (current round) & $(0.40)$ & $(0.33)$ & & \\
& & & $3.210^{* * *}$ & $1.586^{* * *}$ \\
History & & & $(0.13)$ & $(0.33)$ \\
$\quad$ Number of Successful Bribes & & & & \\
(Cumulative) & & & & \\
& 0.005 & -0.264 & $-0.503 * *$ & -0.076 \\
Log Likelihood & $(0.24)$ & $(0.21)$ & $(0.22)$ & $(0.16)$ \\
Chi2 & -75.2 & -100.1 & -78.1 & -117.0 \\
P & 14.46 & 2.32 & 69.21 & 26.04 \\
Observations (Groups) & 0.002 & 0.508 & 0.000 & 0.000 \\
\end{tabular}

$* p<0.1, * * p<0.05, * * * p<0.01$

${ }^{a}$ Fixed effects logit regressions. Table reports coefficients with group-level clustered standard errors in parentheses.

${ }^{\mathrm{b}}$ For models 1 and 2 , the dependent variable takes on a value of 1 if the firm offered a bribe and 0 otherwise. For models 3 and 4, the dependent variable takes on a value of 1 if the government official provided a favor, and 0 otherwise. Models 1 and 3 are for US subjects, while models 2 and 4 are for Pakistan.

${ }^{\mathrm{c}}$ Due to no variation in the dependent variable (i.e. subject always/never offered a bribe/favor), 9 groups ( 90 observations) were dropped from model 1, 15 (150 obs.) groups from model 2, 5 (50 obs.) groups from model 3, and 11 (110 obs.) groups from model 4.

Table A2 Cross-cultural comparisons of punishment

\begin{tabular}{|lcccc|}
\hline & $(1)$ & $(2)$ & $(3)$ & \\
& & & & \\
& Firm Punishment & Government Official Punishment \\
\hline No bribe - No favor & 0.424 & $1.385^{* *}$ & 0.110 & 0.381
\end{tabular}




\begin{tabular}{|c|c|c|c|c|}
\hline & $(0.32)$ & $(0.59)$ & $(0.28)$ & $(0.51)$ \\
\hline No bribe - Favor & $\begin{array}{l}2.150 \\
(1.87)\end{array}$ & $\begin{array}{l}2.801 \\
(1.94)\end{array}$ & $\begin{array}{c}11.820^{* * *} \\
(1.55)\end{array}$ & $\begin{array}{c}11.860^{* * *} \\
(1.56)\end{array}$ \\
\hline Bribe - No favor & $\begin{array}{c}1.302^{* *} \\
(0.51)\end{array}$ & $\begin{array}{c}1.055^{* *} \\
(0.51)\end{array}$ & $\begin{array}{l}0.021 \\
(0.42)\end{array}$ & $\begin{array}{l}0.035 \\
(0.43)\end{array}$ \\
\hline Bribe - Favor & $\begin{array}{c}3.212 * * * \\
(0.58)\end{array}$ & $\begin{array}{c}3.235^{* * *} \\
(0.63)\end{array}$ & $\begin{array}{c}5.292^{* * *} \\
(0.49)\end{array}$ & $\begin{array}{c}5.351 * * * \\
(0.50)\end{array}$ \\
\hline Pakistan X No bribe - No favor & $\begin{array}{c}-0.068 \\
(0.47)\end{array}$ & $\begin{array}{l}-0.124 \\
(0.46)\end{array}$ & $\begin{array}{l}0.287 \\
(0.40)\end{array}$ & $\begin{array}{l}0.333 \\
(0.40)\end{array}$ \\
\hline Pakistan X No bribe - Favor & $\begin{array}{l}-1.001 \\
(2.00)\end{array}$ & $\begin{array}{l}-1.389 \\
(2.00)\end{array}$ & $\begin{array}{c}-6.372^{* * *} \\
(1.65)\end{array}$ & $\begin{array}{c}-6.258^{* * * *} \\
(1.66)\end{array}$ \\
\hline Pakistan X Bribe - No favor & $\begin{array}{c}1.500^{* *} \\
(0.68)\end{array}$ & $\begin{array}{c}1.617^{* *} \\
(0.66)\end{array}$ & $\begin{array}{l}0.040 \\
(0.57)\end{array}$ & $\begin{array}{l}0.199 \\
(0.56)\end{array}$ \\
\hline Pakistan X Bribe - Favor & $\begin{array}{l}-0.690 \\
(0.66)\end{array}$ & $\begin{array}{l}-0.848 \\
(0.65)\end{array}$ & $\begin{array}{c}-2.595^{* * *} \\
(0.56)\end{array}$ & $\begin{array}{c}-2.564 * * * \\
(0.54)\end{array}$ \\
\hline Alternate target punishment & & $\begin{array}{c}-0.079^{*} \\
(0.04)\end{array}$ & & $\begin{array}{c}-0.059^{*} \\
(0.03)\end{array}$ \\
\hline Round \# & & $\begin{array}{c}-0.143^{* * *} * \\
(0.04)\end{array}$ & & $\begin{array}{l}-0.046 \\
(0.03)\end{array}$ \\
\hline Total bribes in pre-crackdown & & $\begin{array}{l}-0.109 \\
(0.11)\end{array}$ & & $\begin{array}{l}0.044 \\
(0.09)\end{array}$ \\
\hline Total favors in pre-crackdown & & $\begin{array}{l}0.134 \\
(0.10)\end{array}$ & & $\begin{array}{l}-0.051 \\
(0.09)\end{array}$ \\
\hline Overall R2 & 0.121 & 0.134 & 0.267 & 0.267 \\
\hline Between R2 & 0.208 & 0.182 & 0.226 & 0.198 \\
\hline Within R2 & 0.093 & 0.120 & 0.296 & 0.306 \\
\hline $\mathrm{P}$ & 0.000 & 0.000 & 0.000 & 0.000 \\
\hline Observations & 730 & 730 & 730 & 730 \\
\hline
\end{tabular}

$* p<0.1, * * p<0.05, * * * p<0.01$

${ }^{a}$ Random effects regressions. Group-level clustered Standard errors in parentheses.

${ }^{\mathrm{b}}$ All models are restricted to the crackdown phase. Model 1 and 2 use citizen expenditure on firm punishment as their dependent variable. Mode1 1 controls for bribe and favor behavior in the triad, while model 2 adds controls for punishment of government official, period, and history. Models 3 and 4 estimate the same specification (as in models 1 and 2) for citizen expenditure on government official punishment.

${ }^{c}$ Models 2 and 4 use punishment of the alternative target as a control. This is because citizens have a combined fixed budget of 15 tokens for punishing both the firm and the official.

Appendix 2: Alternative specification for Table 3 and related discussion.

In the paper, table 3 estimates a random effects probit model for bribes and favors in all rounds.

The round variable ranges from 1 to 10 , such that the intercepts and slopes of each phase are 
directly tested against each other. As an anonymous referee points out, an alternate specification is to replace the round variable with another which ranges from 1 to 30 , to capture the entire trend of the experiment (similar to structural break analysis). This approach tests for structural breaks, under the assumption of a consistent trend across phases. In this appendix, we estimate the model similar to table 3 in the paper, but with the round variable specified as above. This allows us to estimate the change in probability from the end of each round to the beginning of the subsequent round. ${ }^{1}$

Table A3 below estimates a random effects probit model of the probability of offering a bribe in the US and in Pakistan (models 1 and 2 in the table). We regress the dummy variable for offering a bribe (equal to 1 if a bribe was offered) on dummy variables for the crackdown and post-crackdown phases. We use the round number (from 1-30) to account for any trend, as well as interactions between the phases and the round number. Finally, we control for basic demographic characteristics (gender and age).

Taking the US data first, we observe what appears to be a significant negative trend over the course of the experiment, with each successive round reducing the likelihood of a bribe $(p<0.01)$. This trend does not vary by phase, with both the punishment phase and postpunishment phase yielding further insignificant reductions in the probability of offering a bribe $(p=0.23$ and $p=0.74$ for the crackdown and post-crackdown phases respectively). For Pakistan, we also observe a negative trend in bribes, but it is insignificant $(\mathrm{p}=0.39)$, as are the interactions between phases and the trend $(p=0.14$ and $p=0.20)$. The crackdown phase does not have an independent effect at the outset, as we do not observe a significant shift in bribes immediately after the crackdown phase is imposed either in the US $(p=0.51)$, or in Pakistan $(p=0.16)$. Once the crackdown phase ends, however, we observe a significant increase in bribes immediately afterwards, both in the US $(\mathrm{p}<0.05)$ and in Pakistan $(\mathrm{p}<0.05)$.

Favors follow a similar pattern, due to the strong relationship between bribes and favors. In the US, we observe a negative and significant coefficient on the round variable $(\mathrm{p}<0.01)$, which does not significantly differ by phase. In addition, we see no significant change at the

\footnotetext{
${ }^{1}$ Note that most of the coefficients in table A3 are identical to those in table 3 . This is simply because there is one very minor difference between the two tables: the coding of the period variable (ranging from 1 to 10 for table 3 , and from 1 to 30 for table A3). This change impacts the intercepts of the crackdown and post-crackdown phase, but leaves the other estimates unchanged. This is because the re-specification changes the interpretation of the intercepts from direct comparisons with the intercept of the pre-crackdown phase (table 3 ) to comparisons with the trend (i.e. structural breaks: table A3).
} 
onset of the crackdown phase $(\mathrm{p}=0.73)$, but a significant increase in the probability of granting a favor once the crackdown is removed $(\mathrm{p}<0.1)$. By contrast, in Pakistan the probability of providing a favor does not change over time $(\mathrm{p}=0.59)$. In addition, the probability of providing a favor does not significantly increase at the onset of either the Crackdown, or Post-crackdown phases in Pakistan ( $\mathrm{p}=0.45$ and $\mathrm{p}=0.60$ respectively). Thus, it is apparent that in the US, bribes and favors decline over time, but a sharp increase is observed at the beginning of the postcrackdown phase. In Pakistan, we find little evidence of a decline, and also no evidence of a rebound.

Table A3 Regression results for bribe and favor activity in the US and Pakistan - Alternate specification

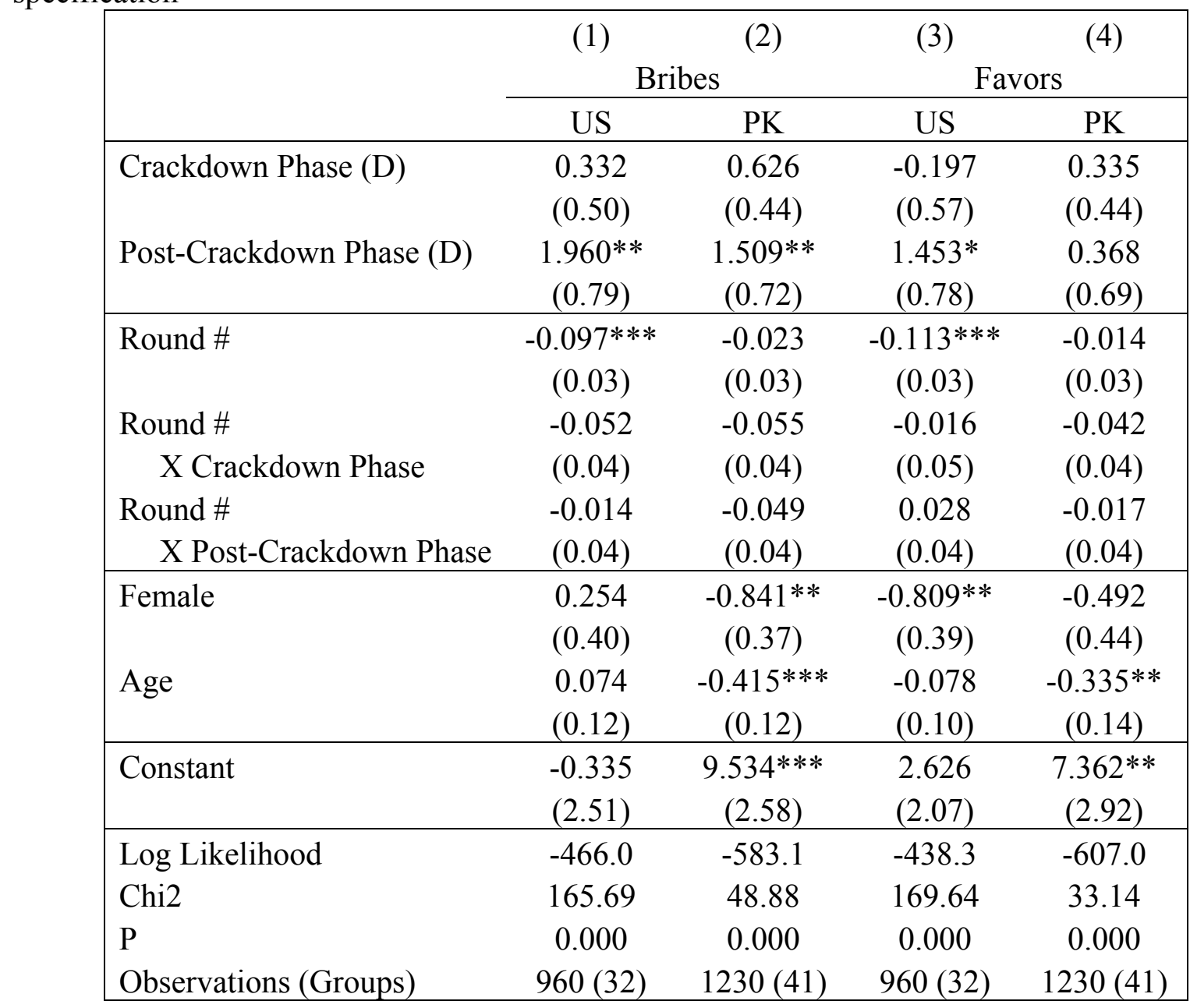

$* p<0.1, * * p<0.05, * * * p<0.01$

${ }^{a}$ Random effects probit regression estimates. Table reports marginal effects with group-level clustered standard errors in parentheses. 
${ }^{\mathrm{b}}$ For models 1 and 2, the dependent variable takes on a value of 1 if the firm offered a bribe and 0 otherwise. For models 3 and 4, the dependent variable takes on a value of 1 if the government official provided a favor, and 0 otherwise. Models 1 and 3 are for US subjects, while models 2 and 4 are for Pakistan.

\section{Declining Bribes and Favors?}

In order to understand the strong apparent decline in bribes and favors over time in the US data, the apparent ineffectiveness of the crackdown phase, and the large increase in corruption following the crackdown, we compare behavior in the Post-crackdown phase with behavior in a related study (Banuri and Eckel 2014), where there is no crackdown phase. In the related study, we conduct sessions consisting of 20 consecutive periods of play without citizen punishment (called "No-Punishment"). These sessions utilize the same game as in the precrackdown and post-crackdown phases of the current study. The only difference between NoPunishment and the current experiment is that the current experiment has 10 rounds where citizens can punish their partners (Crackdown) sandwiched between 20 rounds where citizens are passive (Pre- and Post-crackdown), while No-Punishment features 20 rounds where citizens are passive. The lack of a Crackdown phase eliminates the possibility of a norm signal, or motivation crowding as a direct result of the Crackdown. The key comparison, then, is between rounds 11-20 of No-Punishment (from Banuri and Eckel 2014) with the Post-crackdown phase of the current experiment. ${ }^{2}$

Figure A1 shows bribes and favors in the final 10 rounds of both experiments. In the first 10 rounds of the experiments (not graphed), behavior is virtually identical: Subjects offered bribes in $72 \%$ of all rounds in the current experiment, and $63 \%$ in the No-Punishment experiment $(\mathrm{p}=0.51)$. Similarly, subjects provided favors in $54 \%$ of all rounds in the crackdown experiment, and $56 \%$ in the No-Punishment experiment ( $\mathrm{p}=0.93$ ). Thus for the first ten rounds in the two experiments, the nearly identical protocols produced statically indistinguishable behavior.

In the final ten rounds (graphed), behavior in the post-crackdown phase and in the NoPunishment experiment are nearly identical. ${ }^{3}$ As we can observe from the figures, there is no significant difference in behavior during the final 10 rounds, either in the US, or in Pakistan. In

\footnotetext{
${ }^{2}$ We recruited 183 graduates at the same institutions in the US and Pakistan to participate in the experiments. Note that the treatments are not directly comparable as the data was collected at different times (in February and March 2009; a year earlier). In addition, the parameters and exchange rates were identical in the two years, so the main difference is that subjects in the No Punishment treatment experienced 10 fewer rounds of game play. Any differences due to the (relatively minor) changes in protocol are possible and make direct comparisons difficult. ${ }^{3}$ The No-Punishment experiment protocol informs subjects that they will participate in 20 rounds with fixed partners, while the crackdown protocol informs subjects that they will participate in 30 rounds with fixed partners.
} 
the US, subjects bribed in $63 \%$ percent of the final ten rounds in the crackdown experiment, compared to $58 \%$ in the No-Punishment data $(\mathrm{p}=0.77)$. Similarly, US subjects provided favors in $52 \%$ of the final ten rounds in the crackdown data, compared to $48 \%$ in the No-Punishment data $(\mathrm{p}=0.81)$. Differences across these data are not significant in Pakistan either: subjects offered bribes in $60 \%$ of the final ten rounds in the crackdown data, which is not significantly different from $61 \%$ of rounds in the No-Punishment data $(\mathrm{p}=0.94)$. Favors were provided at $47 \%$ and $60 \%$ in the crackdown and No-Punishment data respectively, yielding no significant differences $(\mathrm{p}=0.38)$. We find no significant differences in bribe and favor behavior in the postcrackdown phase when compared with behavior in an experiment where the crackdown does not occur. This comparison challenges the interpretation of the post-crackdown change in behavior as an increase in corruption: It implies that behavior is simply returning to pre-crackdown levels of corruption.

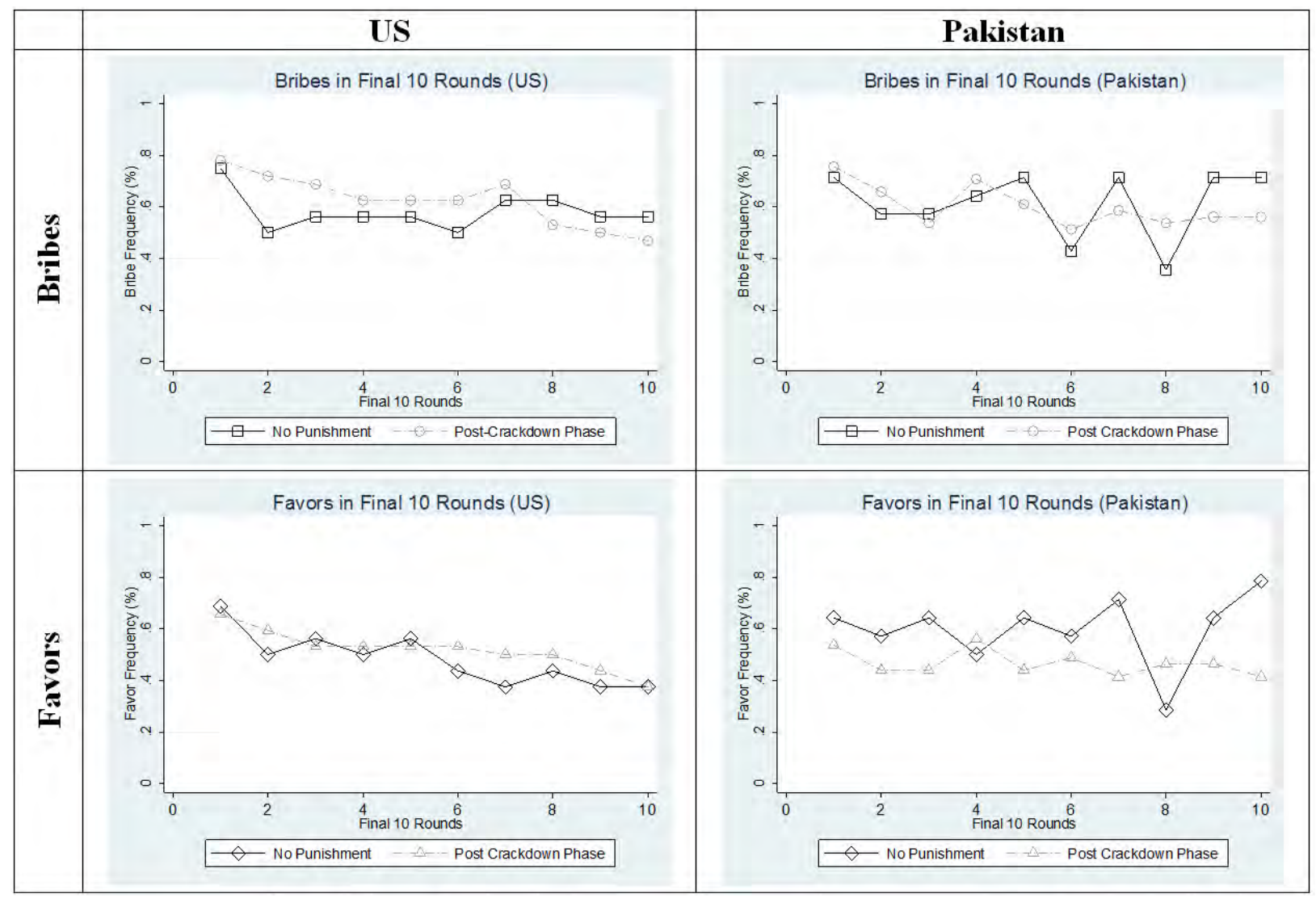

Fig. A1 Impact of crackdown in the final 10 rounds. Graphs compare behavior in the final 10 rounds of the "No Punishment" experiment (where the crackdown phase never occurred) to the final 10 rounds of the crackdown experiment, directly following the crackdown phase ("Post crackdown phase"). 


\section{Appendix 3: Game Instructions and Screenshots \\ Pakistan instruction screenshots:}

Welcome to the decision-making experiment. Please take a moment to turn off your cell phones and put away all outside materials. There will be no taking during the entire session. If you have a question, please raise your hand and an experimenter will hetp you.

You will be paid for this session based the money you accumulate within the session in addition to the Rs. 200 show-up fee. The money that you will accumulate within the session will be based on your decisions, as well as the decisions of your group members.

As you walked in, we had you pick an index card with a number on it. This number is your IO number. We use this number to ensure your anonymity. The data that we will collect today will in no way be linked to you personally Please take a moment to make sure the number on your index card corresponds to the number on the compuler terminal Hold on to the card, it will serve as your claim check for your payment

Please be sure to read all the instructions on each page carefully. Once you click on the "continue" button you will not be allowed to go back.

You will participate in three tasks for today's session. Each task will start with instructions followed by a short quiz to test your understanding of the task.

After the three tasks have been conducted you will be given a survey to complete and then will be paid. We will be using a currency called tokens" in the session. You will be paid according to all tokens accumulated throughout the session.

Each token that you eam today will be exchanged for rupees at 0.4 rupees per token (in addition to the Rs. 200 show-up fee)

Note that each task keeps track of tokens eamed seperately so be sure to write down tokens eamed in each task so that there are no surprises.

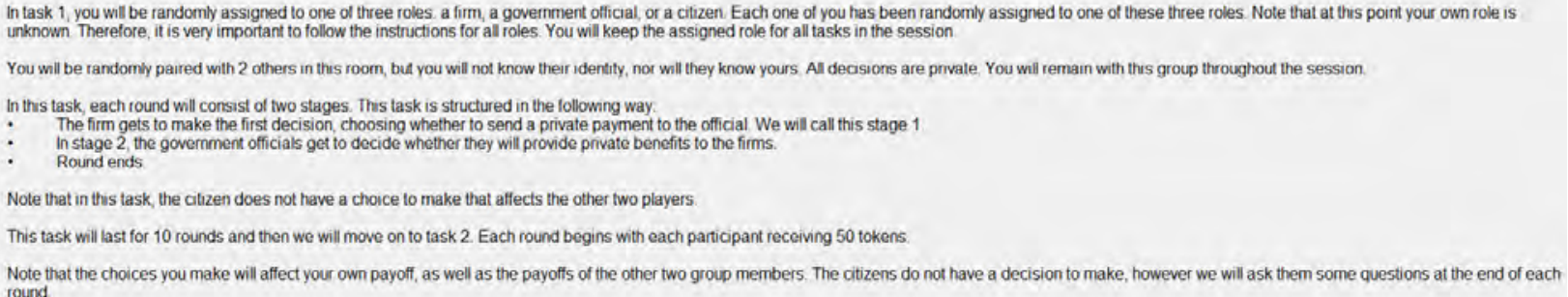

After stage 2, the citizen will be given two questions to answer. After that, the round has ended. Remember that the final amount that you will be paid is based on the total tokens accumulated throughout the session

We will now cover important aspects of the computer interface that you will use to enter your decisions.

The interface consists of 4 sections that will be covered in the next 4 pages.

Please click the button below to continue.

\section{The Round and Time section}

The top of your screen contains the round and time section. This section provides 2 pieces of information, the current round number at the far left, and the time remaining for the decisions at the far right (as shown above) Note that you will have 15 seconds to make your decisions (athough if you go over in the first round, it's OK)

Please click the button below to continue

\section{The Structure section}

Just below the round and time section, you will lind the structure section (as shown above). This is a reminder of the structure of the program. Note that when you are making your decsion, the text lor that decision will be bolded It is a handy way to remind yourself of the overall structure of the task, and which decision gets made first For example, note that the text in the middle is bolded This means that the government officials are currenty making their decisions.

Please cick the button below to continue 
Just below the structure section, you will find the calculations section of the program. This area shows you the effects of each decision on each player's amounts. Note that the calculations start at the left, and as each decision is made in each stage, the cells of this table will update with the appropriate gains / losses in order to give you the final amount at the right. This section will continually update throughout each round

Please click the button below to continue.

\section{The Decision section}

The remaining bottom haf of the screen is the decision section (as shown below). This area is where you will enter your decisions, and will also get information throughout the task. This area will give you information on you role, the round history, the actual decision, and a reminder of the decision consequences

Please click the button below to continue.

Let's go through a quick example to get you used to the interface as well as to describe the layout and structure of this task. Note that this is an example only, once the task begins you will be free to make any decision you prefer First imagine you have been assigned to the role of the firm. Once you click the button below, you will see a decision form for the firms.

Please click the button below to continue.

This is the decision form of the firm. In the structure section above, note how the text "Firm's decide to send private payments" is bolded. This tells all individuals in the room what decision is currently being made. In the decision section below, note that this screen reminds you of the decision you need to make and the consequences of each decision.

In this example let's suppose you would like to send a private payment to the official. Please go ahead and click the "Send a private payment" button below.

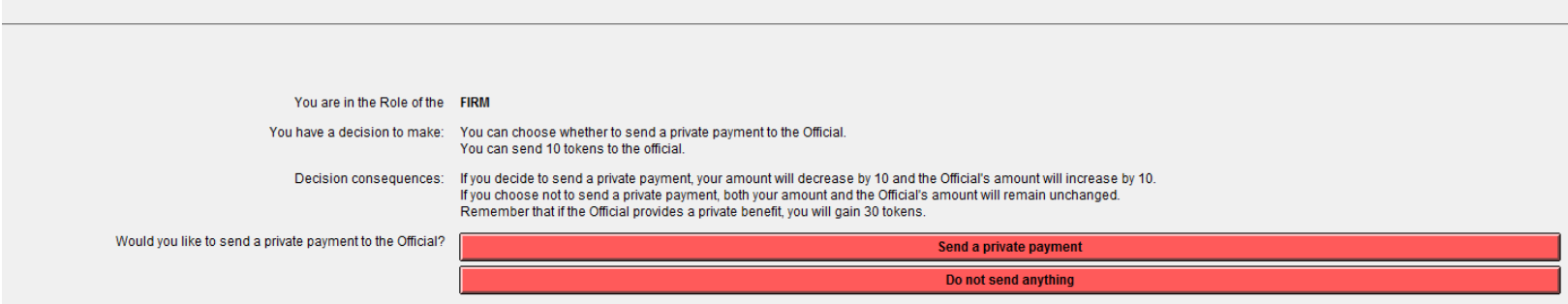

\begin{tabular}{|c|c|c|c|c|}
\hline & Intal Amourts & 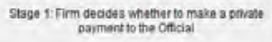 & 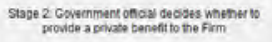 & Teats \\
\hline The Fer & so & -10 & & 40 \\
\hline The officis & 50 & +10 & & во \\
\hline The c cInzen & 50 & & & 80 \\
\hline
\end{tabular}

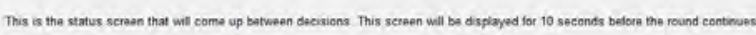

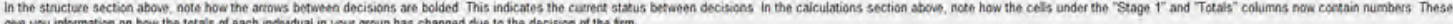
gre you intom acon on thow

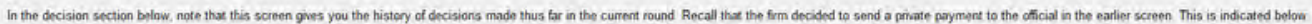

Flasse cick the butition below to contenve

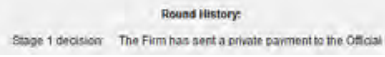


This is the decision form of the government official. In the structure section above, note how the text "Official's decide to provide private benefits" is bolded. This tells all individuals in the room what decision is currently being made. In the decision section below, note that this screen reminds you of the decision you need to make and the consequences of each decision. Also note that it provides you with information on the firm's decision. In this example let's suppose you do not provide a private benefit to the firm. Please go ahead and click the "Do not provide anything" button below.

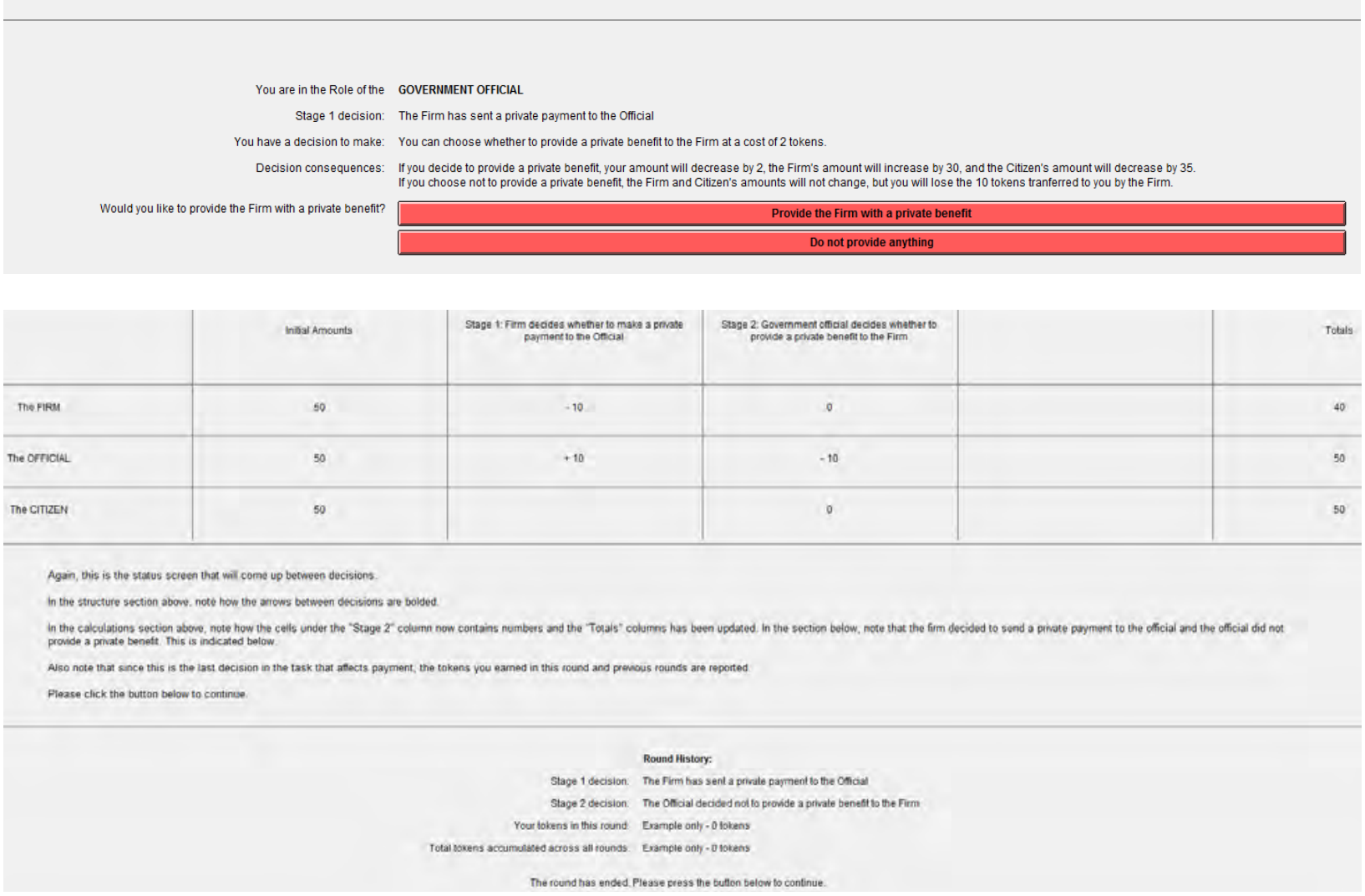

On the next screen you will be given a quiz to test your understanding of task 1. Please raise your hand if you have any questions. Once you have successfully answered all questions the task will begin. Remember that you have been randomly assigned to a role and will keep that role for the entire session. You have also been randomly assigned to a group and will remain in that group for the remainder of the session. There will be 10 rounds of play in task 1 . Instructions for task 2 will begin once everyone in the room has made their decisions. You will be paid for all tokens earned throughout the session.

Please click the button below to continue.

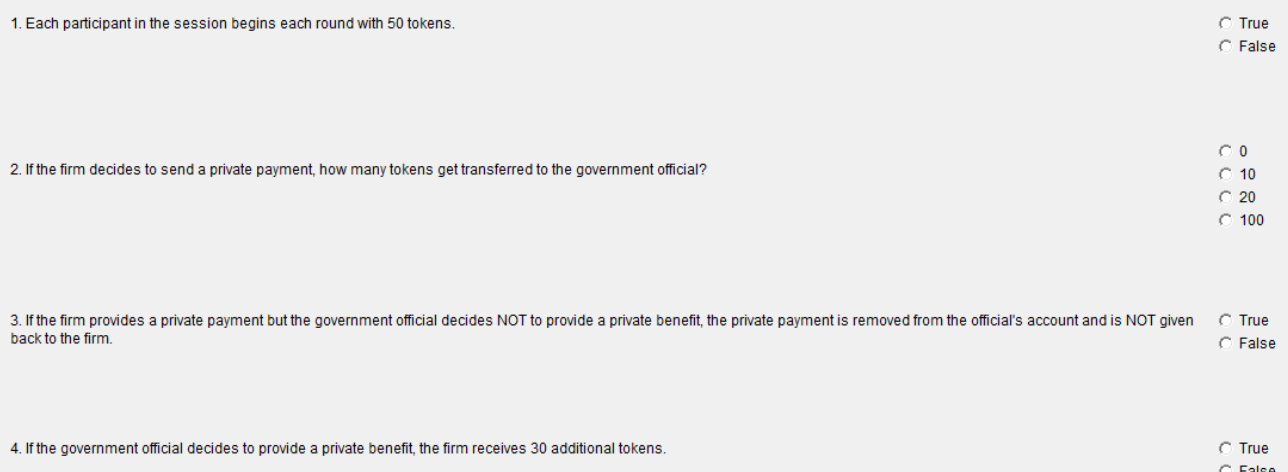


5. If the government official decides to provide a private benefit, how many tokens does the citizen lose?

6. In order to provide a private benefit, government officials have to pay 2 tokens.

We are now ready to begin task 1 . From this point till the end of this task, all decisions made will affect your payment for the session. Remember that each token accumulated in the session is worth 0.4 rupees (in addition to the Rs. 200 show-up fee). Your earnings will be determined by all tokens accumulated throughout the session.

$$
\text { This is Round: } 1 \text { of } 10
$$

You are in the Role of the FIRM 


\section{Task 2 Instructions Supplement:}

\section{Stage 1: Firm's decision}

First, the firm decides whether he/she wants to send a private payment to the government official.

If the firm offers a private payment, then the credit of the firm is reduced by 10 tokens. This amount is transferred to the government official.

If the firm does not offer a private payment, then the tokens remain unchanged.

\section{Stage 2: Government official's decision}

The government official decides on whether to provide a private benefit to the firm (at a cost of 2 tokens).

If the government official provides a private benefit:

- Firm receives 30 additional tokens,

- Government official pays 2 tokens,

- Citizen loses 35 tokens.

If the government official does not provide a private benefit:

- Firm receives 0 tokens,

- Government official forfeits the 10 tokens paid by the firm if the firm made a private payment, and receives 0 otherwise. Note that the firm does not get the 10 tokens back.

- Citizen receives 0 additional tokens.

\section{Stage 3: Citizen's decision}

Now the citizen decides whether or not to reduce the payoffs of the firm and/or the government official. The citizen can choose to pay an amount, and then the payoffs of the firm or government official or both, are reduced by 2 times the amount spent.

If the citizen chooses not to reduce the payoffs:

- Firm receives 0 tokens,

- Government official receives 0 tokens,

- Citizen receives 0 tokens.

If the citizen chooses to reduce the payoffs:

- Firm loses 2 times the amount of tokens spent by the citizen on reducing the firm's payoffs,

- Government official loses 2 times the amount of tokens spent by the citizen on reducing the official's payoffs,

- Citizen chooses how much he/she spends to reduce payoffs, the citizen can pay between 1 and 15 tokens for either the firm or the official or both.

For example, if the citizen chooses to spend $\mathbf{5}$ tokens on reducing the firm's amount and $\mathbf{4}$ tokens on reducing the government official's amount, then the citizen's credit is reduced by 9 tokens $(5+4)$, the firm's credit is reduced by 10 tokens $(5 * 2)$, and the government official's credit is reduced by 8 tokens $(4 * 2)$.

\section{Please record your total earnings for Task 2 below: Total Tokens Earned in Task 2:}

